Georgia State University

ScholarWorks @ Georgia State University

Computer Information Systems Faculty

Publications

Department of Computer Information Systems

2008

\title{
Understanding Digital Inequality: Comparing Continued Use Behavioral Models of the Socio-economically Advantaged and Disadvantaged
}

\author{
J.J. Po-An Hsieh \\ Georgia State University, jjhsieh@gsu.edu \\ Arun Rai \\ Georgia State University, arunrai@gsu.edu \\ Mark Keil \\ Georgia State University, mkeil@gsu.edu
}

Follow this and additional works at: https://scholarworks.gsu.edu/cis_facpub

Part of the Management Information Systems Commons

\section{Recommended Citation}

J.J. Po-An Hsieh, Arun Rai, and Mark Keil, "Understanding Digital Inequality: Comparing Continued Use Behavioral Models of the Socio-economically Advantaged and Disadvantaged," MIS Quarterly, 2008, 32(1), pp. 97-126.

This Article is brought to you for free and open access by the Department of Computer Information Systems at ScholarWorks @ Georgia State University. It has been accepted for inclusion in Computer Information Systems Faculty Publications by an authorized administrator of ScholarWorks @ Georgia State University. For more information, please contact scholarworks@gsu.edu. 


\section{UNDERSTANDING DIGITAL INEQUALITY: COMPARING CONTINUED USE BEHAVIORAL MODELS OF THE SOCIO-ECONOMICALLY ADVANTAGED AND DISADVANTAGED ${ }^{1}$}

By: J. J. Po-An Hsieh

Department of Management and Marketing

Faculty of Business

Hong Kong Polytechnic University

Hung Hom, Kowloon

HONG KONG

jj.hsieh@polyu.edu.hk

\section{Arun Rai}

Center for Process Innovation and

Department of Computer Information Systems

Robinson College of Business

Georgia State University

Atlanta, GA 30303

U.S.A.

arunrai@gsu.edu

Mark Keil

Department of Computer Information Systems

Robinson College of Business

Georgia State University

Atlanta, GA 30303

U.S.A.

mkeil@gsu.edu

\footnotetext{
${ }^{1}$ Deborah Compeau was the accepting senior editor for this paper. Traci Carte was the associate editor. Pamela Carter, Craig Van Slyke, and Jolie Chi Yee Lam served as reviewers.
}

\begin{abstract}
Digital inequality is one of the most critical issues in the knowledge economy. The private and public sectors have devoted tremendous resources to address such inequality, yet the results are inconclusive. Theoretically grounded empirical research is needed both to expand our understanding of digital inequality and to inform effective policy making and intervention. The context of our investigation is a city government project, known as the LaGrange Internet TV initiative, which allowed all city residents to access the Internet via their cable televisions at no additional cost. We examine the residents' post-implementation continued use intentions through a decomposed theory of planned behavior perspective, which is elaborated to include personal network exposure. Differences in the behavioral models between socio-economically advantaged and disadvantaged users who have direct usage experience are theorized and empirically tested. The results reveal distinct behavioral models and isolate the key factors that differentially impact the two groups. The advantaged group has a higher tendency to respond to personal network exposure. Enjoyment and confidence in using information and communication technologies, availability, and perceived behavioral control are more powerful in shaping continued ICT use intention for the disadvantaged. Implications for research and practice are discussed.
\end{abstract}

Keywords: Digital divide, digital inequality, IT policy, technology acceptance, socio-economic inequality 


\section{Introduction}

The Internet represents tremendous opportunities for advancing social, economic, educational, and governmental development (U.S. Advisory Council on the National Information Infrastructure 1996). However, digital inequality between individuals with different backgrounds prevents the socio-economically disadvantaged from exploring digital opportunities (Lenhart 2002; OECD 2001). Digital inequality, in this research, refers to inequality in the access and use of information and communication technologies (DiMaggio et al. 2004). Survey studies have indicated that digital inequality exists across a variety of demographic, ethnic, and geographic dimensions (Katz and Aspden 1997; Lenhart 2002; NTIA 1998, 1999, 2000, 2002; OECD 2001). Among these dimensions, income and education-which suggest one's socio-economic status-have exhibited the most significant power in distinguishing use or nonuse of information and communication technologies (ICT) (Jung et al. 2001; Lenhart 2002). Other factors also tend to correlate with these two. Thus, in this study, we use income and education to differentiate between the socio-economically advantaged and disadvantaged and focus on their behavioral differences in using ICT.

Digital inequality is a substantial global problem, even in developed countries such as the United States. Quite ironically, the United States (birthplace of the Internet) has fallen behind in the household adoption of high-speed Internet. One reason for this is digital inequality. Ranked fourth worldwide by OECD in 2001, U.S. high-speed Internet penetration slipped to twelfth in 2006. In a similar ranking by International Telecommunication Union, the United States slipped from thirteenth in 2004 to sixteenth in 2005. This relative slowdown in high-speed Internet penetration signals a problem that may threaten future U.S. economic development, governmental efficiency, social structure, and ultimately the ability to compete in the global market.

Digital inequality is a complex, multifaceted, problem and there is growing recognition that material, cognitive, and social resources are required to address it effectively (De Haan 2004; Payton 2003; Van Dijk and Hacker 2003). Much of the previous research on digital inequality has focused on descriptively profiling adoption rates, or the extent of ICT access, among advantaged versus disadvantaged groups (De Haan 2004; DiMaggio et al. 2001). ${ }^{2}$ While examining trends in digital inequality is useful, these studies have been cri-

\footnotetext{
${ }^{2}$ Adoption in most digital inequality literature refers to having ICT access (e.g., NTIA 2000, 2002); similarly, adopters, or "the haves," usually refers to individuals who have ICT access.
}

ticized as atheoretical (DiMaggio et al. 2001; Kvasny 2002). To confront the problem substantively and to guide future policy initiatives, digital inequality researchers have emphasized the importance of developing a theoretical understanding of the how and why questions related to the phenomenon (DiMaggio et al. 2001). In this research, we draw on both sociology literature and the theory of planned behavior to explore differences in continued use behavior between socio-economically advantaged and disadvantaged groups in response to a government sponsored initiative to address digital inequality.

Many people stubbornly cling to the belief that digital inequality can be solved by addressing a single factor: technology access (e.g., Kvasny 2002; Van Dijk and Hacker 2003). As a result, most governmental digital inequality initiatives have emphasized technology access. One problem with these technology-centered initiatives is that they assume that technology access is the key hurdle to overcome (DiMaggio et al. 2001; Kvasny 2002). However, we know from prior literature, which has examined a variety of ICT (e.g., e-mail, Windows, e-banking, text editor, Web, etc.), that providing technology access and creating conditions for its initial usage is only the first step and does not guarantee continued intention to use ICT (e.g., Agarwal and Prasad 1997; Bhattacherjee 2001; Davis 1993; Karahanna et al. 1999; Szajna 1996). This line of research has indicated that understanding post-implementation acceptance is essential as benefits from ICT occur through sustained use. Consistent with the research in this literature stream, we use the general term user acceptance to represent individuals' continuance usage intention of the sponsored technology (e.g., Agarwal and Prasad 1997; Szajna 1996). To recap, government initiatives to implement ICT will not alter the state of digital inequality unless there is continued use.

Unfortunately, limited theoretical understanding exists on what it takes to sustain continued use intention among the socio-economically disadvantaged. Government policy makers often make the implicit assumption that the advantaged and disadvantaged will respond to the same technology in similar ways (Hoffman et al. 2001). But, is this assumption valid? Will the drivers of continued use intention be the same and exert similar influence for the advantaged and the disadvantaged when they are provided access to the same technology? The purpose of this study is to gain a better understanding of user acceptance of ICT provided to citizens through a governmental digital inequality initiative. Toward this end, we investigate differences in the underlying factors affecting continued use intention for socio-economically advantaged and disadvantaged groups by comparing their behavioral intention models. The above discussion leads to our major research question: 
In the context of governmental digital inequality initiatives that provide ICT access, how do the overall behavioral models for continued use compare for the socio-economically advantaged and disadvantaged?

\section{Theory, Research Model, and Hypotheses}

\section{Digital Inequality}

Norris (2001) argued that digital inequality relates to deeper patterns of social inequality. While there exist various forms of social inequality, DiMaggio et al. (2004) specifically indicated the need to investigate socio-economic inequality among those who have ICT access. They urged scholars to examine whether people with different socio-economic backgrounds have different behavioral patterns and whether these behavioral differences may diminish once everyone has easy access to ICT. When it comes to understanding digital inequality, the focus on socio-economic inequality is quite reasonable, especially given that income and education exert the most power in explaining use and nonuse (Jung et al. 2001; Lenhart 2002).

Socio-economic inequality has been associated with differential behavioral patterns in such fields as sociology, marketing, education, health psychology, and child development. Socio-economic status essentially brings about a synergy of social and economic forces that derive from assets internal to individuals and resources contained in their surrounding environments (Bornstein and Bradley 2003). Life factors such as income, education attainment, health status, unemployment rate, mortality rate, and so on tend to correlate and be distributed unequally across the socioeconomic continuum in a gradational pattern that is unfavorable to the socio-economically disadvantaged (Bornstein and Bradley 2003; Williams 1990). Consequently, these distinctions have been construed as internal and external resources, or constraints, that, together, shape experiences and opportunities, living and working conditions, place in society, and even ways in which the world is viewed (Mayer and Buckley 1970; Williams 1990). What is especially challenging for the disadvantaged is that when encountering constraints in these resources, factors related to behavioral control can have more serious behavioral consequences than would be experienced by the socio-economically advantaged, leading to an unequal impact that further marginalizes the disadvantaged (e.g. Fan and Eaton 2001; Kessler 1979; Krause and Stryker 1984, Wheaton 1985; Williams 1990).
In this research, we view digital inequality from a socioeconomic perspective; and the behavior of interest to us relates to the continued use of ICT after the technology has been made available. Surprisingly, the phenomenon of digital inequality has seldom been studied from the theoretically rich perspective of ICT acceptance. Consistent with calls for more theory-based research into the psychological factors affecting digital inequality (DiMaggio et al. 2001; Jackson et al. 2001), we use a theory of planned behavior (TPB) perspective to identify and compare post-implementation behavioral intention models for the socio-economically advantaged and disadvantaged. The basic TPB model was elaborated to tap into the complex social and behavioral aspects associated with the digital inequality phenomenon.

\section{Theory of Planned Behavior as the Theoretical Framework}

Psychological theories, such as the technology acceptance model (TAM), the theory of reasoned action (TRA), and the theory of planned behavior (TPB), have been applied to study ICT acceptance, including post-implementation ICT acceptance by individuals who have interaction experience with the technology (i.e, Davis 1993; Hong et al. 2006; Szajna 1996; Taylor and Todd 1995a). Since digital inequality concerns disproportionate ICT innovation behavior, psychological theories for ICT acceptance provide an excellent base to advance theoretical development of this phenomenon. Specifically, TPB is suggested as an ideal framework for understanding ICT acceptance in homes (Venkatesh and Brown 2001), as well as acceptance by individuals who have had some usage experience (Taylor and Todd 1995a). TPB suggests that attitudes (A), subjective norms (SN), and perceived behavioral control (PBC) will influence the individual's behavioral intention, which will in turn determine the individual's behavior (B). Unlike other theories that have been applied to examine ICT acceptance (e.g., TRA and TAM), TPB captures information about social and behavioral control factors (Mathieson 1991; Taylor and Todd 1995b). As these factors are crucial to understand digital inequality (Kvasny 2002), TPB serves as an ideal theoretical foundation for this study.

In this study, we are concerned with causal mechanisms that shape continued use intention in a volitional use context. Specifically, the context is one where, through the implementation of an initiative designed to address digital inequality, individuals have not only received the technology and information about it but also have direct experience with the use of the technology. These conditions, then, enable individuals to form stable behavioral intentions for continued use in the 
future. While behavioral intention is the best predictor for future behavior when the behavior is volitional and the individual has the information to form stable behavioral intentions (Ajzen 1991; Karahanna et al. 1999; Sheppard et al. 1988), some researchers have recommended investigating actual behavior (e.g., Kim and Molhotra 2005). This may be especially useful when investigations are concerned with the causal mechanisms other than behavioral intention that influence behavior in non-volitional or quasi-volitional contexts or when the focus is on the consequences of ICT use. Figure 1 presents the research model with continued use intention specified as the dependent variable of interest. TPB is displayed in Block 1. Table 1 lists construct definitions and sources.

Consistent with TPB, attitude should affect continued use intention for both the advantaged and the disadvantaged. However, it is also important to consider Triandis's (1971) argument that the impact of social norms decreases once behavior takes place. After gaining direct experience, individuals turn to their own experience to evaluate behavioral consequences, and rely less on referents' opinions. In the context of ICT, evidence has shown that the influence of SN on behavioral intention attenuates after individuals have used the technology, as their attention shifts more toward outcome expectations (Karahanna et al. 1999). Thus prior research would suggest that for individuals who have usage experience, attitude should have a stronger impact on continuance intention than SN (i.e., $\beta 1>\beta 2$ as in Figure 1).

Our first hypothesis relates to the differential effect of PBC on continued use intention for the advantaged and disadvantaged. Prior work has suggested that socio-economic status can moderate the relationship between behavioral control and its consequences (Hoffman 2003; Kessler 1979). For example, comparably stressful events can have more serious influence on the socio-economically disadvantaged (SED) than their advantaged peers (Kessler 1979). Stressors, such as divorce, lack of parental supervision, or chronic illness, have a stronger negative impact on children from disadvantaged than advantaged socio-economic backgrounds (Fan and Eaton 2001; Hoffman 2003). It is also the case that the socioeconomically disadvantaged (SED) with poor health habits have worse health than the socio-economically advantaged (SEA) who exhibit the same health behaviors (Pratt 1971). The core argument is that equivalent levels of sense of control differentially impact the socio-economically advantaged and disadvantaged groups, and constrain the disadvantaged more (Krause and Stryker 1984; Wheaton 1985; Williams 1990). While sense of control describes one's expectancy about control over life behavior in general, perceived behavioral control in TPB refers to control over a specific behavior of interest (Ajzen 1991). Although the target behavior may differ in scope, both concepts concern individuals' belief in their ability to control behavior. Accordingly, we expect PBC to have a greater influence on continued use intention for the socio-economically disadvantaged than for the socioeconomically advantaged.

\section{H1: Socio-economic status will moderate the positive relationship between perceived behav- ioral control and continued use intention such that the relationship is stronger for the SED group than for the SEA group.}

\section{Decomposing TPB}

Following Taylor and Todd (1995b) and Venkatesh and Brown (2001), we decomposed the three TPB belief constructs. This decomposition can generate managerial information about specific factors that influence continuance intention. With the aim of providing guidance to policy makers in the formulation of initiatives to address digital inequality, we decomposed the TPB belief constructs to reflect specific underlying factors based on a detailed literature review.

\section{The Attitudinal Belief Structure (Block 2)}

Drawing on motivation theory, Davis et al. (1992) differentiate between extrinsic motivation and intrinsic motivation for ICT usage. In their study of the determinants of ICT acceptance at home, Venkatesh and Brown (2001) identified two key attitudinal beliefs: utilitarian outcomes (UO) and hedonic outcomes (HO) (see Table 1 for construct definitions). ${ }^{3}$ Utilitarian outcomes refers to the expected utility gained by using the technology. Individuals' attitudes toward using an ICT will change as their evaluation of the behavioral outcomes changes (Davis 1989; Davis et al. 1989). Hedonic outcomes refers to the enjoyment derived from the process of using an ICT (Venkatesh and Brown 2001). IS researchers have pointed to the importance of the hedonic aspect of ICT usage as a determinant of household ICT innovation behavior (e.g., Van der Heijden 2004; Venkatesh and Brown 2001). For decades, researchers in consumer behavior have acknowledged that people have differential dispositions toward utilitarian or hedonic behaviors (e.g., Holbrook 1986; Venkatraman and MacInnis 1985). Recent digital inequality studies have also found that the socio-economically disadvantaged, particularly

\footnotetext{
${ }^{3} \mathrm{UO}$ approximates the concept of perceived usefulness.
} 


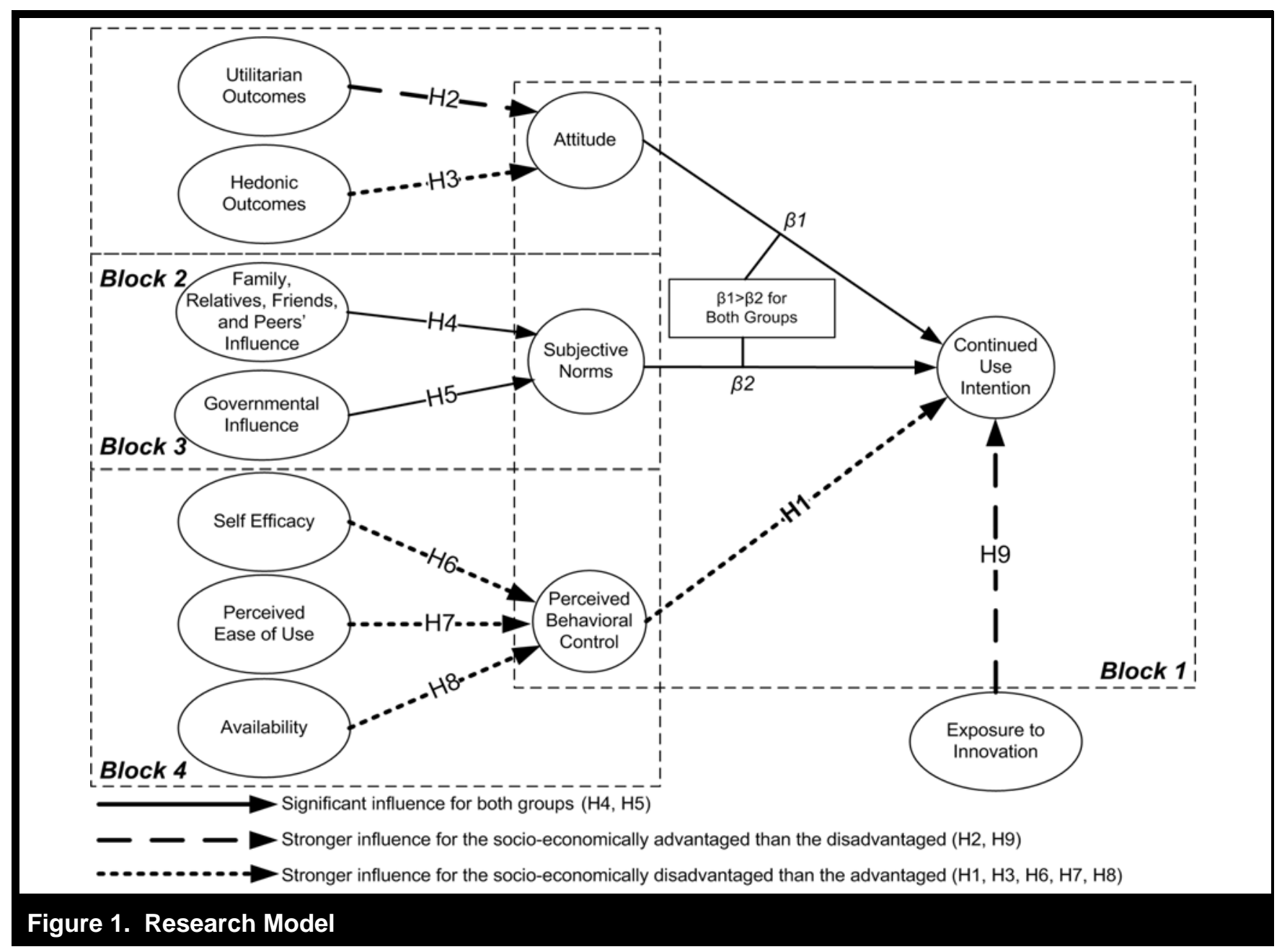

those with lower education attainment, tend to use ICT more for entertainment purposes, while the advantaged tend to use ICT in an instrumental way (Bonfadelli 2002; Shah et al. 2001).

A theoretical explanation for the differential nature of ICT usage by the socio-economically advantaged and the socioeconomically disadvantaged is that the pleasure and satisfaction derived from using a technology is more important for the disadvantaged, whereas the utility obtained from using a technology is more critical for the advantaged. As the SEA are better educated and tend to have more access to and experience with ICT (Norris 2001; NTIA 1999), they are in a better position than the SED to appreciate utilitarian ICT usage. Moreover, the SED exhibit greater tendencies than the SEA for hedonic activities, such as gambling and substance abuse, to avoid life difficulties that they believe to be out of their control (Parker and Endler 1996). As the hedonic use of ICT permits people to immerse in a virtual world and escape from reality (Venkatesh and Brown 2001), we suggest the SED will place more importance on the hedonic impact of ICT use than the SEA. Thus, in determining ICT innovation behavior, utilitarian outcomes may have a higher impact for the socioeconomically advantaged, while hedonic outcomes may have a higher impact for the socio-economically disadvantaged.

H2: Socio-economic status will moderate the positive relationship between utilitarian outcomes and attitude such that the relationship is stronger for the SEA group than for the SED group.

H3: Socio-economic status will moderate the positive relationship between hedonic outcomes and attitude such that the relationship is stronger for the SED group than for the SEA group. 


\begin{tabular}{|c|c|c|}
\hline Construct & Definition & Sources that Inform Construct \\
\hline Attitude & Individual's evaluation of the behavior of interest & Ajzen 1991; Ajzen and Madden 1986 \\
\hline $\begin{array}{l}\text { Utilitarian Outcomes } \\
\text { (UO) }\end{array}$ & $\begin{array}{l}\text { The extent to which performing the behavior } \\
\text { enhances the effectiveness of personal related } \\
\text { activity }\end{array}$ & $\begin{array}{l}\text { Davis 1989; Rogers 2003; Venkatesh } \\
\text { and Brown } 2001\end{array}$ \\
\hline Hedonic Outcomes $(\mathrm{HO})$ & $\begin{array}{l}\text { The pleasure and inherent satisfaction derived from } \\
\text { performing the behavior of interest }\end{array}$ & $\begin{array}{l}\text { Davis 1989; Venkatesh 1999; } \\
\text { Venkatesh and Brown } 2001\end{array}$ \\
\hline Subjective Norms (SN) & $\begin{array}{l}\text { The perceived expectation from an individual's key } \\
\text { referents to perform the behavior of interest }\end{array}$ & Ajzen 1991; Ajzen and Madden 1986 \\
\hline $\begin{array}{l}\text { Family, Relatives, } \\
\text { Friends, and Peers' } \\
\text { Influence }\end{array}$ & $\begin{array}{l}\text { The perceived expectation from family, relatives, } \\
\text { friends and peers for an individual to perform the } \\
\text { behavior of interest }\end{array}$ & $\begin{array}{l}\text { Karahanna et al. 1999; Venkatesh and } \\
\text { Brown 2001; Taylor and Todd 1995b }\end{array}$ \\
\hline Governmental Influence & $\begin{array}{l}\text { The perceived expectation from the government } \\
\text { institutions for individuals to perform the behavior of } \\
\text { interest }\end{array}$ & $\begin{array}{l}\text { Lynn et al. 1995; Keil et al. 2003; } \\
\text { Kvasny } 2002\end{array}$ \\
\hline $\begin{array}{l}\text { Perceived Behavioral } \\
\text { Control (PBC) }\end{array}$ & $\begin{array}{l}\text { An individual's perception of existence or } \\
\text { nonexistence of required resources and opportunities } \\
\text { to perform the behavior of interest }\end{array}$ & Ajzen 1991; Ajzen and Madden 1986 \\
\hline Self-Efficacy (SE) & $\begin{array}{l}\text { The belief in one's capabilities to organize and to } \\
\text { execute the course of action required to attain a goal }\end{array}$ & $\begin{array}{l}\text { Bandura 1977; Compeau and Higgins } \\
1995\end{array}$ \\
\hline $\begin{array}{l}\text { Perceived Ease of Use } \\
\text { (PEOU) }\end{array}$ & $\begin{array}{l}\text { The degree to which an individual believes that } \\
\text { performing the behavior of interest would be free of } \\
\text { effort }\end{array}$ & Davis 1989; Davis et al. 1989 \\
\hline Availability & $\begin{array}{l}\text { The availability of the technology to perform the } \\
\text { behavior of interest }\end{array}$ & $\begin{array}{l}\text { Kvasny and Keil 2002; Meader et al. } \\
\text { 2002; Taylor and Todd 1995b }\end{array}$ \\
\hline $\begin{array}{l}\text { Personal Network } \\
\text { Exposure (PNE) }\end{array}$ & $\begin{array}{l}\text { The proportion of adopters in an individual's personal } \\
\text { network }\end{array}$ & $\begin{array}{l}\text { Fligstein 1985; Palmer et al. 1993; } \\
\text { Valente } 1995\end{array}$ \\
\hline Continued Use Intention & The intention to continue using the technology & Ajzen 1991 \\
\hline
\end{tabular}

\section{The Normative Belief Structure (Block 3)}

Evidence suggests that key members from one's social network may exert normative influence upon one's innovation behavior (Valente 1995), since they have more chances to exchange important information (Childers and Rao 1992; Cocanougher and Bruce 1971). Such members may include family, relatives, friends, and peers (Childers and Rao 1992). The subjective norms that shape an individual's behavior will be influenced by expectations from these salient referents (Taylor and Todd 1995b).

H4: Family, relatives, friends, and peers' influence will be positively related to subjective norms for both the SEA and the SED groups.
Government institutions are important in facilitating the diffusion of ICT innovation (King et al. 1994) and reducing digital inequality (DiMaggio et al. 2001). While researchers have suggested the need to study such effects (DiMaggio et al. 2001; Kvasny 2002), few digital inequality studies have examined governmental influence on individual ICT innovation behavior.

Governments that devise initiatives to address digital inequality generally expect these interventions to help citizens, particularly the disadvantaged, access and use ICT, develop digital skills for work opportunities, and eventually attain improvements in quality of life (see Crump and Mcllroy 2003; Kvasny 2002; Van Winden 2001). Studies have found that governments may use systematic approaches to raise 
awareness and interest among citizens about these initiatives. They can use different media channels, including communicating directly with citizens, to explain the benefits of using ICT and to offer training and technical support (e.g., Kvasny 2002; Van der Meer and Van Winden 2003). From the citizen's perspective, these institutional efforts to encourage and facilitate ICT use convey the message that the government is committed to their interests and has taken their needs and requirements into consideration (Kvasny 2002). In fact, prior research has revealed that government agencies may serve as important referents whose expectation affects individual innovation acceptance (Lynne et al. 1995). Thus, governmental expectation may influence individuals' ICT innovation behavior. In this research, the governmental influence construct captures this perceived governmental expectation.

\section{H5: Governmental influence will be positively related to subjective norms for both the SEA and the SED groups.}

\section{The Behavioral Control Belief Structure (Block 4)}

Based on the literature review, PBC is decomposed into three important behavioral control factors: self-efficacy (SE) (Taylor and Todd 1995b), perceived ease of use (PEOU) (Ajzen 1991; Mathieson 1991), and availability (Lenhart 2002).

Self-efficacy has long been suggested as the key determinant for behavioral control (Bandura 1977) and for ICT implementation (Compeau and Higgins 1995). Moreover, Eastin and LaRose (2000) have argued that self-efficacy is critical in understanding digital inequality. Empirically, studies have revealed that self-efficacy affects ICT usage (Eastin and LaRose 2000) and that a lack of confidence, or self-efficacy, is one of the most important factors deterring the disadvantaged from accessing and using ICT (see Bishop et al. 2001; Crump and Mcllroy 2003). Researchers have also suggested that psychological factors associated with an individual's sense of control may affect the socio-economically disadvantaged to a greater degree than the socio-economically disadvantaged (e.g., Kessler 1979; Krause and Stryker 1984; William 1990). For example, studies have shown that selfefficacy plays a more important role in affecting perceived health and depression for those in difficult socio-economic conditions than those who are better off (Schwarzer and Jerusalem 1995). Following this logic, SE should have a stronger influence on PBC for the disadvantaged.

H6: Socio-economic status will moderate the positive relationship between self-efficacy and per- ceived behavioral control such that the relationship is stronger for the SED group than for the SEA group.

Ajzen and his colleagues (Ajzen 1991; Ajzen and Madden 1986) claimed that PBC is related to the perceived ease or difficulty in conducting a behavior. Specifically, Ajzen (1991) noted that PBC “refers to people's perception of the ease or difficulty of performing the behavior of interest" (p. 183). Most IS studies in the past have positioned PEOU as an attitudinal determinant (e.g., Davis 1989). Some have alternatively suggested that PEOU is associated with behavioral control (e.g., Mathieson 1991; Venkatesh 2000). The logic for this association is that the ease or difficulty of ICT use affects individuals' beliefs about the control they have on the use of the technology. Recent empirical evidence also supports this view of PEOU being associated with behavioral control in the contexts of home PC acceptance (Brown and Venkatesh 2005; Venkatesh and Brown 2001) and of electronic commerce (Pavlou and Fygenson 2005). Consistent with this stream or research, we treat PEOU as a behavioral control belief.

Technological complexity is one major barrier that causes ICT nonuse (Lenhart 2002), and people strongly desire easyto-use technologies (Katz and Aspden 1997). When facing a difficult challenge, the advantaged, relative to the disadvantaged, can more flexibly and effectively cope with issues to neutralize downside effects (Fan and Eaton 2001; Kessler 1979; Pearlin and Schooler 1978). In this vein, when interacting with an ICT, the relatively higher educational attainment of the advantaged should enable them to more flexibly cope with the complexity embedded in the technology, thus minimizing the impact of the difficulty or ease in operating the technology on their perceived control. Therefore, PEOU should have a stronger impact for the socio-economically disadvantaged than the advantaged.

\section{H7: Socio-economic status will moderate the posi- tive relationship between perceived ease-of-use and perceived behavioral control such that the relationship is stronger for the SED group than for the SEA group.}

Prior digital inequality studies have indicated that cost and availability are barriers that prevent people, especially the disadvantaged, from successfully using ICT (Lenhart 2002). Given that government digital inequality initiatives tend to subsidize the financial expenditure of ICT access, this study focuses on the availability issue.

Availability, or the accessibility of the technology when needed, represents another behavioral barrier, especially for 
the socio-economically disadvantaged. In many situations, technological access is provided in theory; but in practice, the technology may not be available when people want to use it. In a study about the use of a computer resource center, Taylor and Todd (1995b) suggested that if there were not enough computers available for all the students who wanted to use the center concurrently, this might represent a barrier for ICT use. Therefore, when there are more users than units of technologies, or the competition for access is high, availability can surface as a behavioral barrier. If such availability constraints emerge for ICT implemented through a governmental digital inequality intervention, the disadvantaged's lower disposable economic and material resources, in comparison to the advantaged's, puts them in a weaker position to address it. Such a constraint is, therefore, expected to have a greater influence on PBC for them.

H8: Socio-economic status will moderate the positive relationship between availability and perceived behavioral control such that the relationship is stronger for the SED group than for the SEA group.

\section{Personal Network Exposure}

Since innovations often involve uncertainty and many innovations have low visibility, an individual's innovative behavior can be influenced strongly by how other members in that individual's personal network respond to the innovation (Valente 1995, p. 70). Valente (1995) proposed the construct personal network exposure (PNE) which represents the cumulative proportion of adopters in one's personal network. While subjective norms in TPB captures one aspect of social influence, it does not capture the aggregate personal network exposure. Further, subjective norms focus solely on the "expectation" from "important others," while PNE accounts for the "observed" aggregate behaviors in one's overall personal network. Therefore, PNE is conceptually distinct from subjective norms.

Valente contended that the larger the proportion of individuals in one's personal network that are engaged in an innovation behavior, the more likely it is that the individual will take on the same behavior. The direct effect from personal network exposure to continued use intention represents this causal mechanism. The concept of perceived critical mass introduced by Lou et al. (2000) and Li et al. (2005) represents a related construct, which refers to the degree to which a person believes that most of his or her peers are using a particular innovation (Lou et al. 2000). As in the case of PNE, individ- uals with a higher perceived critical mass will have a greater intention to continue using the technology ( $\mathrm{Li}$ et al. 2005; Lou et al. 2000).

We offer two reasons - one relates to prior experience and the other relates to education - on why personal network exposure should have a stronger effect on the socio-economically advantaged than the disadvantaged.

First, individuals have a tendency to interpret information in a way that is more congruent with their prior experience and preexisting knowledge structure (Bobrow and Norman 1975; Klapper 1960). Studies have found the SEA in general have greater ICT access and use (Lenhart 2002; NTIA 1998, 1999, 2000); and the SED tend not to view ICT as a priority of daily living, especially those for whom life is a day-to-day struggle (Crump and Mclloy 2003). Arguably, as the SEA are generally more familiar with ICT relative to the SED, information about ICT innovation, such as from personal networks, should be more consistent with their experience and knowledge structures.

Second, the higher education of the SEA relative to the SED allows them to more readily access and comprehend information signals related to ICT innovations (De Haan 2004). Their education facilitates the absorption and comprehension of information (Hilgard and Bower 1975), such as from personal networks, and makes them more responsive to innovation triggers that require thought stimulation and cognitive effort (Venkatraman and Price 1990).

The above arguments on prior experience and resource conditions suggest that the SEA may be more susceptible to the influence of personal network exposure than the socioeconomically disadvantaged.

H9: Socio-economic status will moderate the positive relationship between personal network exposure and continued use intention such that the relationship is stronger for the SEA group than for the SED group.

\section{Control Variable}

The existence of an alternate mode of Internet access in the household may reduce an individual's need to use whatever Internet access is offered through public policy interventions aimed at addressing digital inequality. Since a PC is the dominant mode of household Internet access, the ownership of an Internet PC was measured and used as a control variable for continued use intention. 


\section{Research Method}

\section{The Free Internet TV Initiative in LaGrange, Georgia}

LaGrange, with a population of 27,000, is located 60 miles southwest of Atlanta, Georgia. The LaGrange city government, unlike most municipal governments in the United States, finances their operation by collecting sales tax and generating revenue by providing services without charging property tax (Keil et al. 2003; Meader et al. 2002). The services offered include electricity, natural gas, sanitation, and telecommunications to both commercial and residential customers. In the 1990s, the city government created a twoway $750 \mathrm{MHz}$ hybrid coaxial and fiber-based system with 18 fiber optic nodes around the city. Each node further connects between 500 and 900 households via coaxial cable. In addition to cable TV and broadband services offered via this infrastructure, in April 2000, city officials devised a three-way contract with the cable company (Charter Communications) and an Internet service provider (Worldgate Communications) to use the excess bandwidth to provide an Internet TV service to every household at no additional cost. Thus, residents were able to receive household Internet service without paying anything beyond the basic cable fee of $\$ 8.70$ per month. ${ }^{4}$ One of the chief aims of this city-wide initiative was to address digital inequality.

The Internet TV used a television-based Internet access device. Subscribers received a free wireless keyboard and digital set-top-box, which connected the cable and TV. Users could use the wireless keyboard to browse the Internet via their TV. At the rate of 158 Kbits per second, the connection speed was nearly three times higher than the typical dial-up service (56 Kbits/sec). Subscribers also enjoyed unlimited access, a free e-mail service, $5 \mathrm{MB}$ of web space, and a technical support hotline that was available seven days a week (Keil et al. 2003). Training was available in the community center, over cable TV, as well as through the technical support hotline. The Internet TV was user-friendly in that users did not have to install or maintain an operating system or application programs. However, the Internet TV did not allow printing, storing files, or browsing websites that required software plug-ins (e.g., Adobe Acrobat and Apple QuickTime). Users also could not use the Internet TV and watch TV simultaneously.

\footnotetext{
${ }^{4}$ Because of poor reception of broadcast TV signals in LaGrange, the majority of the population has the cable connection. In those few cases where a household wanted to use LITV but could not afford the cable fee, the city was willing to provide free cable connection.
}

The LaGrange Internet TV (LITV) initiative is believed to be the first project in the world in which a city government offered free high-speed Internet access and service to every household (National Public Radio 2000). Compared to a typical Internet PC, the Internet TV was easier to use, yet more limited in its capability. Still, the Internet TV represented a chance to connect for those who might not otherwise explore high-speed household Internet access and all that it has to offer. The LITV initiative provided a unique opportunity to study post-implementation ICT acceptance across socio-economically advantaged and disadvantaged groups in response to a government initiative designed to eliminate economic barriers and provide universal access. Our interest here was to evaluate how the behavioral intention models for continued use differed across the two groups.

\section{Data Collection}

A survey instrument was developed to collect the quantitative data needed for model and hypothesis testing. For most constructs in the research model, Likert-type scale items were adapted from existing measures (see Appendix C). Following prior research measuring the proportion of adopters in a social system (Fligstein 1985; Palmer et al. 1993), a single item using a 10-level interval scale ranging from 0 to 100 percent was used for personal network exposure. The survey instrument was pretested with 20 subjects from LaGrange and minor modifications were made prior to its full-scale administration.

In summer 2003, the survey instrument was administered to all LaGrange households of record who had implemented the digital set-top boxes needed to use the Internet TV. According to the city's records, this included approximately 3,500 households, or 38.9 percent of the 9,000 eligible households. The survey was mailed to each household where the LITV had been implemented, with two waves of reminder postcards mailed one week and three weeks after the initial survey. The adult member of the household who had used LITV the most was requested to respond to the survey.

In all, 526 residents responded to the mail survey, indicating that the government had implemented the technology within their homes and that they had used it, yielding a raw response rate of 15.03 percent. $^{5}$ Adjusting for the number of non-

\footnotetext{
${ }^{5}$ As indicated by some researchers, the general response rate for mail survey of the general public has been decreasing to lower than $20 \%, 15 \%$, and even $10 \%$ in the past few decades due to the increasing use of this method (Harbaugh 2002; Steeh 1981). This decline has also been seen in some IS research (Pinsonneault and Kraemer 1993; Ravichandran and Rai 2000).
} 
deliverable surveys, the overall adjusted response rate was 19.5 percent. Finally, after excluding cases with missing or incomplete responses, 451 complete and usable surveys were retained for quantitative analysis. A total of 96 percent of the respondents reported first using LITV at least one year prior to the data collection, and the remaining 4 percent first used it between two and six months prior to the data collection. Thus, all respondents had direct experience with the technology for a sufficient time to formulate stable intentions of their future LITV usage.

To investigate possible nonresponse bias, a wave analysis was conducted to compare the indicators of key constructs as well as demographic profiles between the early and late respondents. Since the second wave postcard reminder was mailed three weeks after the initial mail, subjects responding within three weeks were classified as early respondents, while those responding later than three weeks were classified as late respondents. A t-test of the key variables collectively showed that the late respondents were quite similar to the early ones, suggesting that if there is any nonresponse bias, it would be minimal.

To further examine the issue of nonresponse bias, we adopted the general procedure used by Ravichandran and Rai (2000). Telephone interviews were conducted with 140 randomly sampled nonrespondents. Interviewees were asked about reasons for nonresponse. The top three reasons for nonresponse were (1) did not like to fill out any survey or threw it away (28 percent), (2) did not receive survey (27 percent), and (3) too busy and did not have time to complete the survey (14 percent). The main reasons given for nonresponse were general issues that would be expected in any survey research and were not topic relevant. However, a small portion of nonrespondents' reasons might be specific to the survey theme, such as "did not know anything about computers" (2 percent), and/or "did not like LITV" (5 percent). While caution should always be exercised when generalizing from survey data, there appears to be little or no evidence of a threat from nonresponse bias.

As discussed earlier, income and education, which suggest one's socio-economic status, have proven to be strong predictors for ICT use (Jung et al. 2001; Lenhart 2002). These two variables ${ }^{6}$ were therefore used to classify subjects as socio-economically advantaged or disadvantaged using Ward's method of hierarchical cluster analysis (Hair et al. 1998). The analysis yielded two clusters with 307 socioeconomically advantaged subjects in one and 144 disad-

\footnotetext{
${ }^{6}$ Both income and education level were operationalized as ordinal scales. No indication of nonresponse bias was observed on these two variables.
}

vantaged subjects in the other. As expected, a comparison of the two groups' profiles reveals considerable difference (see Tables 2 and 3). The socio-economically disadvantaged relative to the advantaged were more likely to have lower income and education level and consist of more elder and younger, African American, and female individuals. Such a profile is consistent with the findings in most national surveys (NTIA 1998, 1999, 2000, 2002).

Next, to verify the representativeness of the respondents, in terms of income and education, and that of the classified advantaged and disadvantaged, two additional analyses were performed. Public data containing the median household income and average education level for each census block in the city of LaGrange were acquired from the U.S. Census Bureau. The correlations of household income, as well as education level, between the survey and census data across all census blocks were calculated. The high correlation values obtained (Table 4) support the representativeness of the survey respondents relative to the LaGrange population.

To further evaluate the representativeness of the extracted clusters, a ratio of the number of advantaged respondents to the number of the disadvantaged for each block group was computed. In effect, this ratio characterizes the socioeconomic status of a block group. As can be seen in Table 5, the ratio demonstrated high correlation with both the census median household income and average education level across all block groups, indicating that the extracted clusters are representative of the advantaged and disadvantaged groups in the city of LaGrange.

\section{Data Analysis and Results}

\section{Measurement Model}

Partial least squares (PLS), which uses component-based estimation, maximizes the variance explained in the dependent variable, does not require multivariate normality of the data, and is less demanding on sample size (Chin 1998). For these reasons, PLS-Graph 3.0 was used for the data analysis. The measurement and structural models were first evaluated separately for the socio-economically advantaged and disadvantaged groups, before cross-group comparisons were conducted.

For the measurement model, each construct was modeled to be reflective, with one exception: FRPF is modeled as formative. Its items, which tap into influence from friends, family, relatives, and peers, do not necessarily have to covary, are not interchangeable, and the direction of causality is from the items to the latent construct (Jarvis et al. 2003). 


\begin{tabular}{|c|c|c|}
\hline & Disadvantaged & Advantaged \\
\hline \multicolumn{3}{|l|}{ Household Income } \\
\hline$<10,000$ & $28.8 \%$ & $0.0 \%$ \\
\hline $10,000-14,999$ & $23.7 \%$ & $0.0 \%$ \\
\hline $15,000-24,999$ & $38.1 \%$ & $4.3 \%$ \\
\hline $25,000-34,999$ & $8.5 \%$ & $14.5 \%$ \\
\hline $35,000-49,999$ & $0.9 \%$ & $22.7 \%$ \\
\hline $50,000-74,999$ & $0.0 \%$ & $22.7 \%$ \\
\hline $75,000-99,999$ & $0.0 \%$ & $14.2 \%$ \\
\hline$>=100,000$ & $0.0 \%$ & $21.6 \%$ \\
\hline \multicolumn{3}{|l|}{ Education Level } \\
\hline Some Elementary/High School & $20.9 \%$ & $0.0 \%$ \\
\hline High School Diploma & $64.4 \%$ & $26.2 \%$ \\
\hline College Degree & $14.7 \%$ & $42.4 \%$ \\
\hline Post Graduate & $0.0 \%$ & $31.4 \%$ \\
\hline \multicolumn{3}{|l|}{ Age } \\
\hline $18-30$ & $11.4 \%$ & $5.7 \%$ \\
\hline $31-40$ & $15.0 \%$ & $12.2 \%$ \\
\hline $41-50$ & $19.3 \%$ & $26.1 \%$ \\
\hline $51-60$ & $14.3 \%$ & $22.7 \%$ \\
\hline$>60$ & $40.0 \%$ & $33.3 \%$ \\
\hline \multicolumn{3}{|l|}{ Gender } \\
\hline Male & $18.6 \%$ & $44.3 \%$ \\
\hline Female & $81.4 \%$ & $55.7 \%$ \\
\hline \multicolumn{3}{|l|}{ Ethnic Group } \\
\hline White American & $15.9 \%$ & $40.3 \%$ \\
\hline African American & $81.8 \%$ & $53.5 \%$ \\
\hline Other & $2.3 \%$ & $6.2 \%$ \\
\hline
\end{tabular}

\section{Table 3. Comparison of Demographics between Disadvantaged and Advantaged}

\begin{tabular}{|l|c|c|c|c|}
\hline Test & \multicolumn{2}{|c|}{ Mann-Whitney Test } & \multicolumn{2}{c|}{ Chi-Square Test } \\
\hline Statistics & Z-Score & Sig. & Sig. \\
\hline Income & -15.22 & 0 & \multicolumn{2}{c|}{ Not Applicable } \\
\hline Education & -10.97 & $\mathbf{0}$ & \multicolumn{2}{c|}{ Not Applicable } \\
\hline Age & -0.22 & $\mathbf{0 . 8 2 4}$ & $\mathbf{4 8 . 0 1}$ & 0 \\
\hline Gender & \multicolumn{2}{|c|}{ Not Applicable } & 55.14 & 0 \\
\hline Ethnic & \multicolumn{2}{|c|}{ Not Applicable } & \\
\hline
\end{tabular}


Table 4. Correlation Between Survey and Census Data Across All Block Groups

\begin{tabular}{|l|c|}
\hline \multicolumn{1}{|c|}{ Dimension } & Correlation \\
\hline Median Household Income (Survey Data versus Census Data) & 0.83 \\
\hline Average Education Attainment (Survey Data versus Census Data) & 0.85 \\
\hline
\end{tabular}

Table 5. Correlation between Advantaged Versus Disadvantaged Ratio and Census Data

\begin{tabular}{|l|c|}
\hline \multicolumn{1}{|c|}{ Dimension } & Correlation \\
\hline $\begin{array}{l}\text { Ratio (\# of advantaged / \# of disadvantaged) versus Median Household Income (Across } 30 \text { block } \\
\text { groups) }\end{array}$ & 0.81 \\
\hline $\begin{array}{l}\text { Ratio (\# of advantaged / \# of disadvantaged) versus Average Education Attainment (Across } 30 \\
\text { block groups) }\end{array}$ & 0.84 \\
\hline
\end{tabular}

For all constructs, the internal consistency and convergent validity were evaluated by examining the item-constructloading, composite reliability, and average variance extracted (AVE). ${ }^{7}$ For individual item reliability, item loadings are higher than 0.707 (Chin 1998) (see Appendix A). As shown in Table 6, the values of composite reliabilities are all higher than 0.707 (Nunnally and Bernstein 1994), and values of AVE are all above 0.50 (Fornell and Larcker 1981). Next, discriminant validity was assessed by examining if the squared correlation between a pair of latent variables was less than the AVE associated with each construct (Appendix B1 and B2). Furthermore, we calculated item cross-loadings based on the procedure recommended for PLS (Gefen and Straub 2005). Each item loaded higher on its principal construct than on other constructs (Appendix A). While cross-loadings derived from this procedure will be inevitably higher than from typical exploratory factor analysis (Gefen and Straub 2005), the cross-loading differences were much higher than the suggested threshold of 0.1 (Gefen and Straub 2005). These results collectively suggest good measurement properties for both groups. Table 6 also lists the means and standard deviations for constructs.

\footnotetext{
${ }^{7}$ When formative constructs exhibit high internal consistency, retaining multiple indicators is problematic due to multicollinearity problems (Jarvis et al. 2003). In these situations, such as with FRPF in our case (average correlation equals 0.92 for the SED, 0.95 for the SEA), a linear composite based on unit means of indicator scores can be used. Given the high correlation among the indicators, this unit mean-based index score is naturally highly correlated with index scores derived using alternate weighting schemes (Rozeboom, 1979). Moreover, the use of unit means, as opposed to factor scores, is recommended when new measures are used and transferability is desired (Hair et al, 1998). Accordingly, we use a unit meanbased index score for FRPF in subsequent analysis.
}

\section{Structural Model}

With an adequate measurement model in place, the structural model was independently tested for socio-economically advantaged and disadvantaged groups. A bootstrap analysis was performed with 500 subsamples, with sample size set equal to the SEA and SED sample sizes ( $n=307$ and $n=144$, respectively). The resulting models for both groups explained a significant amount of variance in the dependent and mediating variables. Figure 2 presents the standardized path coefficients and the explained construct variances.

As noted earlier in the theory section, the proferred knowledge from the technology acceptance literature is that attitudes play a greater role than social norms in shaping the behavioral intention for individuals who have had direct experience in using the technology. While we requested respondents who had used LITV the most in the household to participate in the survey, the collected data enabled us to evaluate the relative influence of attitudes and subjective norms on continued use intention. As can be seen in Figure 2, for both groups, the path from attitude to BI is significant, whereas the path from SN is not. In addition, the association between attitude and $\mathrm{BI}$ is indeed significantly higher than the association between $\mathrm{SN}$ and $\mathrm{BI}(\mathrm{t}=1.97$ for the SED; $\mathrm{t}=2.5$ for the SEA). ${ }^{8}$ This finding is consistent with past studies on the relative importance of attitude and SN for BI for experienced users, suggesting that the respondents indeed had firsthand LITV usage experience.

\footnotetext{
${ }^{8}$ We used the following equation $\left[\mathrm{T}=\left(\mathrm{r}_{\mathrm{xy}}-\mathrm{r}_{\mathrm{vy}}\right) \cdot \operatorname{sqr}((\mathrm{n}-3)(1+\mathrm{rxv})) / \mathrm{sqr}(2\right.$ $\cdot(1-r 2 x y-r 2 v y-r 2 x v+2 \cdot r x y \cdot r x v \bullet r v y))$, where $x=U O, v=H O, y=$ ATT, $n$ = sample size], as per Cohen and Cohen (1983), to compare the relative strengths of the associations between constructs.
} 
Table 6. Descriptive Statistics and Reliability of Constructs

\begin{tabular}{|c|c|c|c|c|c|c|}
\hline \multirow[b]{2}{*}{ Construct $^{\dagger}$} & \multicolumn{3}{|c|}{ Disadvantaged Group } & \multicolumn{3}{|c|}{ Advantaged Group } \\
\hline & $\begin{array}{l}\text { Mean } \\
\text { (S.D.) }\end{array}$ & $\begin{array}{l}\text { Composite } \\
\text { Reliability }\end{array}$ & AVE $^{\ddagger}$ & $\begin{array}{l}\text { Mean } \\
\text { (S.D.) }\end{array}$ & $\begin{array}{l}\text { Composite } \\
\text { Reliability }\end{array}$ & AVE $^{\ddagger}$ \\
\hline Attitude (3) & $5.76(1.74)$ & 0.99 & 0.98 & $4.86(1.87)$ & 0.99 & 0.96 \\
\hline Utilitarian Outcomes (4) & $5.37(1.83)$ & 0.99 & 0.95 & $4.09(2.18)$ & 0.99 & 0.97 \\
\hline Hedonic Outcomes (3) & $5.69(1.85)$ & 0.99 & 0.98 & $4.27(2.26)$ & 0.98 & 0.97 \\
\hline Subjective Norms (2) & $3.83(2.16)$ & 0.98 & 0.96 & $2.74(2.02)$ & 0.98 & 0.96 \\
\hline Fam., Rel., Fri., \& Peers (1)* & $4.01(2.18)$ & NA & NA & $2.84(2.02)$ & NA & NA \\
\hline Governmental Influence (2) & $4.23(2.27)$ & 0.96 & 0.93 & $3.81(2.12)$ & 0.97 & 0.94 \\
\hline PBC (3) & $5.77(1.59)$ & 0.95 & 0.85 & $6.05(1.49)$ & 0.95 & 0.87 \\
\hline Self-Efficacy (3) & $5.89(1.68)$ & 0.97 & 0.92 & $5.76(1.73)$ & 0.97 & 0.92 \\
\hline Perceived Ease of Use(4) & $5.49(1.80)$ & 0.95 & 0.82 & $4.96(1.87)$ & 0.93 & 0.78 \\
\hline Availability(2) & $2.57(1.73)$ & 0.90 & 0.82 & $2.52(1.55)$ & 0.88 & 0.79 \\
\hline Continued Use Intention (3) & $4.91(2.37)$ & 0.98 & 0.95 & $3.31(2.55)$ & 0.99 & 0.96 \\
\hline Personal Network Exposure(1) & $0.42(0.29)$ & NA & NA & $0.31(0.26)$ & NA & NA \\
\hline Internet PC Ownership (1) & $0.20(0.40)$ & NA & NA & $0.66(0.47)$ & NA & NA \\
\hline
\end{tabular}

*Influence of family, relatives, friends, and peers is a formative construct whose score is computed as a unit mean of four items.

${ }^{\dagger}$ The number in parentheses indicates the items in the scale. ${ }^{\ddagger}$ Average Variance Extracted.

\section{Multi-Group Analysis for Differences Across Advantaged and Disadvantaged Groups}

To test our hypotheses associated with differential behavioral impact, we compared the coefficients of individual paths between the two structural models. This analysis is similar to a test of the moderation effect of socio-economic status on the path strength across groups. To do so, it was necessary to first assess whether the latent constructs were perceived in a similar fashion between the advantaged and disadvantaged (Carte and Russell 2003). An examination of Appendix A suggests that the loading patterns are the same and factor loadings are very similar, thus permitting between-group path comparison. ${ }^{9}$ Chin (2004) notes that, when variances are not too different across groups, a t-test can be applied to assess statistical differences in path coefficients for each pair of paths. Alternatively, the Smith-Satterthwait (S-S) test with a pooled error term should be used if the variance varies profoundly across groups. Only 2 of the 12 factors exhibit different variance across groups. Given that the variances are not too different, we first examined the path differences using t-tests. To evaluate the stability of these results when an assumption of unequal variance is made, we also applied the $\mathrm{S}-\mathrm{S}$ test. The results from the application of the t-test and the

\footnotetext{
${ }^{9}$ A supplementary measurement invariance analysis was performed to further validate the similarity of measurement models between the two groups. The results in Appendix D provide additional support for measurement invariance.
}

S-S test identify the same set of paths to differ across groups. ${ }^{10}$ The direction of the differences $(>$ or $<$ ) can be evaluated by comparing the estimated coefficients from the two groups. Six pairs of paths were found to be different between the groups (Table 7). Thus, the results of the PLS analysis provide evidence of the moderation effect of socioeconomic status on the behavioral models for continued ICT use.

To further investigate the type of moderation effect of SES, to ensure that the detected moderation was not an artifact of unequal measurement error across subsamples, and to evaluate if the conclusion regarding the type of moderation is sensitive to nonlinear effects of the predictors on the criterion, we applied the moderated regression analysis (MRA) procedure proposed by Sharma et al. (1981). The results of these analyses provide additional evidence in support of SES moderating the strength of relationship between identified criterion and predictor variables (see Appendix F).

In addition to applying moderated regression analysis to validate the moderation effect of socio-economic status, we evaluated if the detected moderation was an artifact of the measurement model, which in PLS is idiosyncratic to the sample. While there is prima facia supporting evidence of identical

\footnotetext{
${ }^{10}$ Our findings are consistent with Chin's (2004) assertion that with sufficient sample size, such as in our scenario, results obtained from the two tests should be similar.
} 


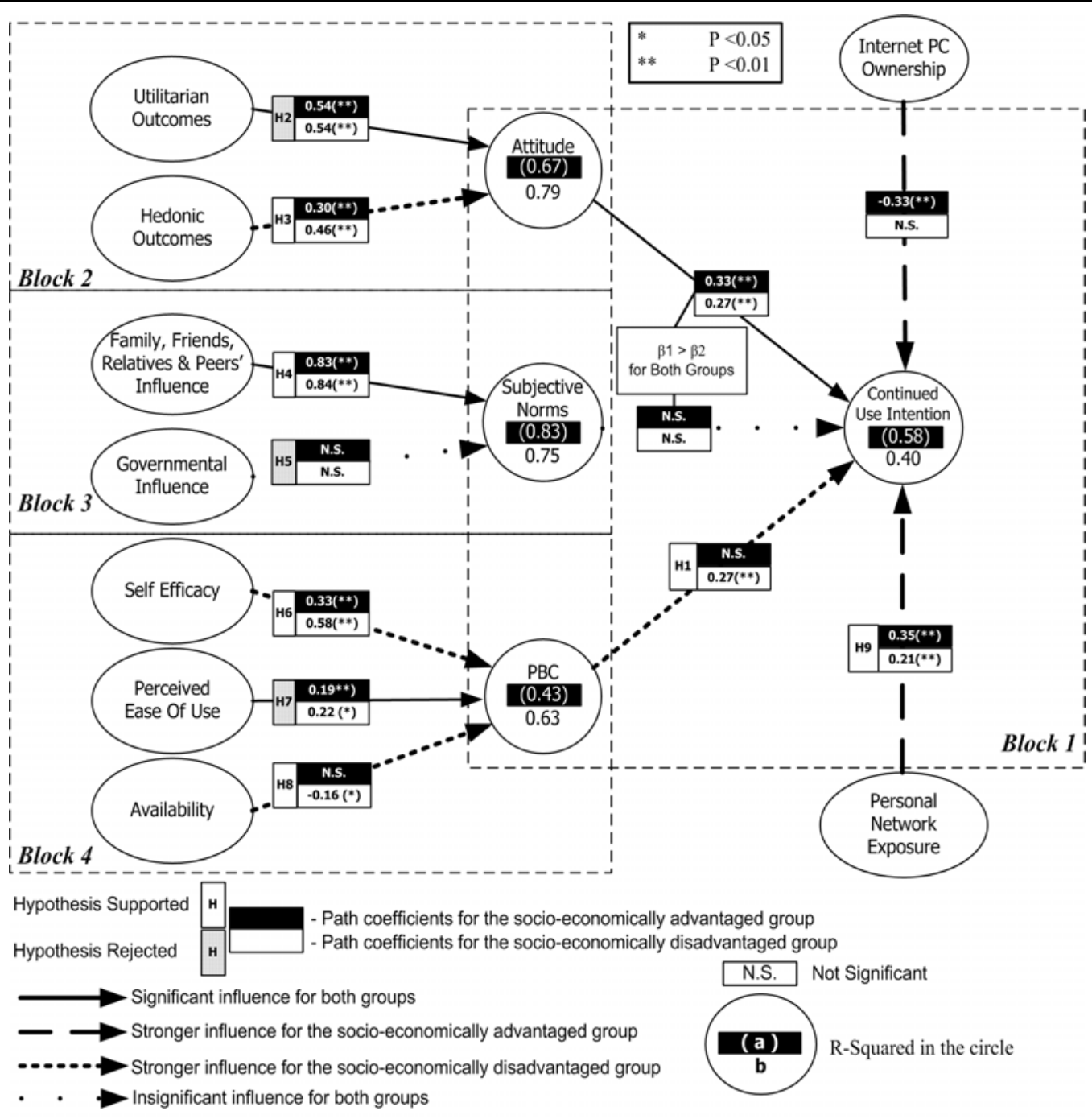

Note: Availability was operationalized in that a higher value maps to a greater constraint.

Figure 2. Structural Model

\section{Table 7. Path Comparison}

\begin{tabular}{|l|l|l|l|}
\multicolumn{1}{|c|}{ Path } & \multicolumn{1}{|c|}{ SE Disadvantaged } & \multicolumn{1}{|c|}{ SE Advantaged } \\
\hline H1: PBC $\rightarrow \mathrm{BI}$ & $0.27(0.084)^{\star \star}$ & $>$ & $0.05(0.039)$ N.S. \\
\hline H3: Hedonic Outcome $\rightarrow$ Attitude & $0.46(0.076)^{\star \star}$ & $>$ & $0.30(0.053)^{\star \star}$ \\
\hline H6: Self-Efficacy $\rightarrow$ PBC & $0.58(0.085)^{\star \star}$ & $>$ & $0.33(0.078)^{\star \star}$ \\
\hline H8: Availability $\rightarrow$ PBC & $-0.16(0.078)^{\star \star}$ & $>$ & $0.07(0.069)$ N.S. \\
\hline H9: Personal Network Exposure $\rightarrow$ BI & $0.21(0.022)^{\star \star}$ & $<$ & $0.35(0.047)^{\star \star}$ \\
\hline Control Internet PC Ownership $\rightarrow$ BI & $-0.09(0.067)$ N.S. & $<$ & $-0.33(0.057)^{\star \star}$ \\
\hline
\end{tabular}

Path coefficient is significant at: ${ }^{* \star} \mathrm{p}<0.01,{ }^{\star} \mathrm{p}<0.05$; N.S.: Path coefficient is not significant.

a. One-tailed tests were performed as the direction of differences was hypothesized.

b. Availability was operationalized such that a higher value connotes a greater constraint.

c. Numbers in parentheses are the standard errors. 
loading patterns and similar item loadings across the samples for the SEA and SED, we used the measurement model results from the other group to compute the latent scores and then reevaluated the structural models. In other words, we computed the latent construct scores for the SEA using the estimated measurement model (item loadings) of the SED and then compared the structural models across the two groups. We repeated this procedure, where we computed the latent scores for the SED using the measurement model (item loadings) of the SEA and, again, compared the structural models across groups. The results are similar to those reported earlier, ruling out the threat that the observed moderating effect is due to idiosyncrasy of loadings associated with the samples.

Finally, given the high proportion of females in the SED sample, we wanted to rule out the possibility that the moderation results detected earlier were because of gender rather than socio-economic status. Prior IS studies have indicated that the influence of some factors on use intention may vary according to gender (e.g., Venkatesh and Morris 2000). To evaluate the moderation role of gender, we split the sample and compared the behavioral models of males and females. Based on these results, there are no common differences between the behavioral models for females and males and between the behavioral models for the advantaged and disadvantaged, with one exception: the path from self-efficacy to PBC is stronger for females than males and for the disadvantaged than the advantaged. Additionally, we compared the behavioral models of SED and SEA female groups. The results reveal similar differences between the behavioral models for SEA and SED females and those between the advantaged and disadvantaged with one exception: there is no difference in the relationship from self-efficacy to PBC between the SEA and SED female groups. Thus, regardless of socio-economic status, gender moderates the relationship between self-efficacy and perceived behavioral control.

We took several actions to address the potential threat of common method bias (CMB). First, the instrument contains different scale formats to reduce scale commonality (Podsakoff et al. 2003). After data collection, we performed the Harmon one-factor test recommended by Podsakoff and Organ (1986). A factor analysis combining independent and dependent variables revealed no sign of a single-factor accounting for the majority of covariance. Next, following the recommendation of Podsakoff et al. (2003) and the analytical procedure used by Liang et al. (2007), we added a common method factor to the PLS model. The indicators of all constructs were associated reflectively with the method factor. Then, each indicator variance explained by the principle construct and by the method factor was computed. The results in Appendix E show that (1) only 3 out of the 31 method loadings are significant, and (2) while the average substantively explained variance for an indicator is 0.906 , the common method-based variance is only 0.003 . In addition, results of the structural models demonstrated different levels of significance for path coefficients. The above evidence collectively suggests that common method bias is not a significant issue in this study.

\section{Discussion}

In total, the results support six of the nine hypotheses (Table 8) and reveal six paths with differential impact between the advantaged and disadvantaged groups (Table 7). Contrary to our expectations, utilitarian outcomes and PEOU had no differential impact, and governmental influence did not influence subjective norms for either group.

\section{Attitudinal Influence and Antecedents}

In line with prior studies, attitude had a stronger influence than SN on continuance intention for our subjects (Figure 2). In determining attitude, hedonic outcomes, as predicted, was marginally more influential for the disadvantaged than the advantaged. However, utilitarian outcomes had no differential impact on attitude across groups, and thus $\mathrm{H} 2$ was not supported. Utilitarian outcomes of ICT can possibly be classified into different levels of sophistication. Given the nature of the technology offered by the government to citizens in our context, the measurement items of UO focused on simple ICT functions like communication and information search. The results revealed no differential motivational influence based on socio-economic status toward using ICT for these basic purposes. Nevertheless, the hypothesized differential motivational impact may be more salient for advanced functions like investment analyses or other complex analytical tasks, since the SEA are more likely to have greater exposure to utilitarian applications and to better understand their potential benefits, thus appreciating these functions more strongly. Future research should further examine this conjecture.

\section{Social Influence: Subjective Norms and Personal Network Exposure}

Subjective norms was primarily shaped by expectation from important referents in one's social network. In contrast, governmental influence was not significant for either group, and thus H6 was not supported. A post hoc analysis revealed that when the path from FRPF to SN was removed, govern- 
Table 8. Hypotheses Testing Results

\begin{tabular}{|c|c|c|}
\hline $\begin{array}{c}\text { Type of } \\
\text { Hypothesis }\end{array}$ & Supported & Not Supported \\
\hline \multirow{4}{*}{$\begin{array}{l}\text { Differential } \\
\text { Impact Across } \\
\text { Groups }\end{array}$} & \multicolumn{2}{|c|}{ Stronger Influence for the Disadvantaged } \\
\hline & $\begin{array}{l}\mathrm{H} 1: \mathrm{PBC} \rightarrow \mathrm{BI} \\
\mathrm{H} 3: \text { Hedonic Outcomes } \rightarrow \text { Attitude } \\
\mathrm{H} 6: \text { Self-Efficacy } \rightarrow \text { PBC } \\
\text { H8: Availability } \rightarrow \text { PBC }\end{array}$ & H7: PEOU $\rightarrow$ PBC \\
\hline & \multicolumn{2}{|c|}{ Stronger Influence for the Advantaged } \\
\hline & H9: Personal Network Exposure $\rightarrow \mathrm{BI}$ & $\mathrm{H} 2$ : Utilitarian Outcomes $\rightarrow \mathrm{BI}$ \\
\hline $\begin{array}{l}\text { Same Impact } \\
\text { Across Groups }\end{array}$ & H4: Family, Relatives, Peers, and Friends' Influences $\rightarrow$ SN & H5: Governmental Influence $\rightarrow$ SN \\
\hline
\end{tabular}

mental influence significantly affected SN. Thus, in the presence of normative influence from one's key referents, government influence does not play a key role in shaping subjective norms. Importantly and consistent with past research, once users have directly experienced using the system, subjective norms is not influential for continued use.

While subjective norms per se was not found to be important, our results suggest that the social network still affects postimplementation ICT acceptance through personal network exposure. As we hypothesized, the effect of PNE was stronger for the advantaged than for the disadvantaged. As delineated earlier, while SN concerns the expectation from "important" referents, PNE focuses on "observing" the aggregate manifest behavior across one’s personal network. The advantaged did indeed appear to be more sensitive in responding to such a signal.

\section{Behavioral Control Influence and Antecedents}

Consistent with our conjectures, perceived behavioral control (PBC), self-efficacy, and availability were more critical in determining continuance intention for the disadvantaged than the advantaged. Note that because gender also had a moderating effect on the path from self-efficacy to PBC, this relationship needs to be probed further in future research. Interestingly, the salient negative impact of availability for the disadvantaged suggests that potential conflict between household members who wanted to watch TV and those who wanted to use the Internet TV may have created accessibility issues. Our probing of this issue through open-ended face-toface discussions with a few respondents from the socioeconomically disadvantaged cluster confirmed that such conflicts were commonplace among household members, with each member wanting to use the same device for different purposes. The functionality of the TV, once a mass media appliance, was expanded to serve as a multi-purpose home device. The elaborated functionality induced competition for this resource, which is an issue that has not surfaced in prior research on ICT acceptance. Such access-related considerations suggest that even when certain services are free, the necessity of sharing the ICT in the case of the SED dampens their perceived behavioral control.

Contrary to our expectation, perceived ease of use had no differential influence across groups, thus H8 was not supported. One possible reason for this insignificant result may be the user-friendly design of the Internet TV, which appears to have addressed the coping challenges that the SED are likely to face when interacting with ICT that is less userfriendly.

Regardless of the impact of SE, PEOU, and availability on PBC, PBC only affected behavioral intention for the disadvantaged. This finding reinforces a key point: even when the technology is made available, disadvantaged individuals still need to deal with psychological and material barriers that are not addressed directly by technology-centered interventions.

\section{Internet PC Ownership}

On average, the advantaged, relative to the disadvantaged, had a higher level of ownership of Internet PCs (66 percent versus 20 percent). This ownership understandably exerted a damping effect on the advantaged's intention to continue using the Internet TV. Interestingly, the disadvantaged's Internet PC ownership had little influence on their continuance intention. Our face-to-face interviews on this issue 
suggest two possible explanations for the insignificant relationship. Some of the disadvantaged, who already had Internet PCs, wanted to use the Internet TV rather than buying another computer, so that other family members could use the existing Internet PC. In this scenario, the Internet TV served as an alternative device to meet the high demand for Internet access within these households. Some disadvantaged, however, participated in the LITV initiative because it allowed them to discontinue their paid Internet service and save the monthly subscription fee. Both explanations, to a certain degree, reflect how the socio-economic status of the disadvantaged may have resulted in Internet PC ownership not having a negative effect on their behavioral intention of continued use.

\section{Summary}

The results suggest very different post-implementation behavioral models, between socio-economically advantaged and disadvantaged groups, in response to LITV, a government sponsored digital inequality intervention that emphasized technology access. Factors that influenced individuals' intention to continue using the technology were different between the two groups. Taken as a whole, 58 percent and 40 percent of the variance in a user's continuance intention were explained by the behavioral models for advantaged and disadvantaged groups, respectively. The discrepancy in the explained variance suggests that there may be additional factors that are relevant to the disadvantaged that deserve further consideration. Such factors may include physical conditions, emotional variables (e.g., fear and anxiety), employment status, family structure (e.g., single parent family), and so forth.

\section{Limitations and Implications}

Digital inequality exists across not only individuals but also nations. The nature of the inequality may vary tremendously across countries with different economic development status (Checchi et al. 2003). While developed countries like the United States are eager to stimulate sustained ICT usage, many underdeveloped nations are still struggling with basic infrastructure. People from different countries may also hold different cultural assumptions toward modern technologies. Thus, while the findings from this study may be extended to other similar technology-centered initiatives, the generalizablity to other nations may be limited to a certain degree.

While digital inequality exists across different socio-demographic dimensions, we focused on socio-economic status as the key distinction between advantaged and disadvantaged groups. Although it is logical and reasonable to use socioeconomic status for classification since it represents a deeprooted inequality in modern society, there may be other dimensions that are worthy of study. Future research, for example, may also look into other groups, such as the disabled, to investigate unique barriers and facilitators of ICT acceptance.

Today, Internet access is becoming available through a broader range of devices, including computers, cell phones, personal data assistants (PDA), Internet TV, and other emerging technologies. Although availability of multiple access mechanisms may influence one's usage of a specific innovation, this research, given its focus on ICT innovation behavior at home, controlled only for the most common form of Internet access, namely household Internet PC onership. Future research could shed more light on the impact of all of these alternative access mechanisms on patterns of home ICT usage.

Finally, this research represents a snapshot of the digital inequality phenomenon. A longitudinal study tracing individuals' pre- and post-implementation behavior may yield a richer understanding of behavioral patterns, critical factors, and how these are shaped over time.

\section{Implications for Theory}

For digital inequality researchers, this study represents an important step toward understanding the problem of digital inequality using a theoretically grounded approach based on the theory of planned behavior. This model addresses the often-cited need to understand the intricacies of user acceptance of ICT in the context of digital inequality (Bonfadelli 2002; Van Dijk and Hacker 2003). It demonstrates that a TPB-based model can explain a significant amount of variance in continued use intention both for advantaged and disadvantaged groups of a government-sponsored technology innovation aimed at providing household Internet access. Most importantly, key between-group differences were theoretically deduced and empirically tested. Thus, from the standpoint of digital inequality, this study constitutes an important theoretical contribution to explain the phenomenon. The observed between-group differences warrant elaboration and further examination as they represent promising avenues for insight into differential behavioral patterns and their causes.

Personal network exposure appears to be a noteworthy factor that is relevant in the context of digital inequality, suggesting that researchers should explore other social influence mechanisms in addition to subjective norms as well as their collec- 
tive effect. For instance, information on high aggregate innovation behavior in the social system provides a cue that reinforces the social desirability of continued use. Similarly, information about the innovation relayed through the mass media (e.g., TV, radio, and newspapers) exerts another type of social influence (Rogers 2003; Venkatesh and Brown 2001). In the early stages of innovation diffusion, since very few people have or know about the innovation, mass media serves as an important information source for early adopters (Rogers 2003; Valente 1995).

This study also responds to the call for increased attention in investigating governmental influence on digital inequality (DiMaggio et al. 2004). Apparently, the technology-centered LITV initiative partially achieved its objective by successfully removing access barriers for citizens. Meanwhile, expectations from key referents overshadowed the effect of governmental expectation in shaping subjective norms, even though these norms had no effect on continued use. Nonetheless, besides financial subsidy, technology supply, and normative expectation, the impact of governmental influence on behavioral intention may operate in other forms such as people's trust in the government (e.g., Meader et al. 2002) and training and support programs (e.g., Kvasny 2002). These different forms of influence suggest additional mechanisms that the government can employ to stimulate user acceptance. A more comprehensive conceptualization of possible mechanisms of governmental influence should further enhance theoretical development and facilitate effective policy formulation. For instance, partnerships between the government and the private sector, in which the former provides training programs and the latter provides appropriate applications and infrastructure, are emerging as potentially powerful mechanisms for addressing digital inequality. Illustratively, Project Shiksha, a Microsoft-sponsored initiative in India, establishes a partnership between state governments, school systems, and Microsoft to promote IT literacy and skills among 80,000 teachers and 3.5 million students in government and government-aided schools (Microsoft 2006).

Finally, prior digital inequality research has ignored alternative benefits from ICT usage. Traditionally, digital inequality researchers have focused on improving one's life chances from technology use. Thus, when the disadvantaged embrace technology for "recreational” purposes, it has been viewed as noncapital-enhancing. Nevertheless, some researchers have indicated that recreational use of various kinds of technologies can have educational value (Prensky 2003), and that hedonic uses of ICT may result in learning that eventually contributes to utilitarian outcomes (e.g., Belanger and Van Slyke 2000). Thus, given our findings that entertainment represents a key factor motivating the disadvantaged to use
ICT, and past findings that recreational use represents a majority of their ICT usage (e.g, Bonfadelli 2002), the value of entertainment in ICT use deserves careful investigation. Researchers in digital inequality should tap into the educational aspect of ICT entertainment and seek to connect the recreational use to skills and/or opportunities that can make the disadvantaged better off.

For the field of technology acceptance, our findings suggest several important theoretical contributions and implications. First, as Legris et al. (2003) noted, although current ICT acceptance theories are useful, incorporating additional critical factors is necessary to improve their explanatory power. This study illustrates that TPB can be meaningfully extended through the addition of personal network exposure, which captures the behavioral consequences of aggregate social informational influence. The addition of the personal network exposure construct explained 10 percent more of the variance in the dependent variable. This strong influence suggests that aggregate signals about the states and trends of ICT usage can be used to shape post-implementation intention to continue use.

Second, the differences in the behavioral models of the SEA and SED groups, particularly in the continued use context, shed light on the importance of developing nuanced theories that can be applied to shape the post-implementation behavior of specific groups. Thus, researchers should not only continue to examine distinctions across diffusion stages but also evaluate how differences among individuals with different backgrounds or characteristics impact ICT acceptance.

As the importance of digital technologies range beyond the scope of organizations, some IS researchers have called for investigating problems relevant to everyone (Lytras 2005). Our study is of particular interest and importance in this respect, as it represents one of the few efforts to investigate ICT innovation behavior in households and beyond typical workplace settings. Specifically, the results identify many key factors that may not be salient in the context of ICT use in organizational settings, yet exert significant influence on individuals' ICT innovation behavior in the context of digital inequality. Behavioral control, for instance, is a critical issue when cognitive and material resources are of concern. This research also identifies a specific form of the social informational mechanism (i.e., personal network exposure) that can powerfully affect individuals’ post-implementation behavior. This result, in particular, extends our understanding from prior IS research that individuals will rely less on social information in shaping ICT behavior after direct interaction with the technology (e.g., Karahanna et al. 1999, Venkatesh and Davis 2000). These findings, as a whole, illustrate the com- 
plexity and dynamics involved in ICT acceptance in nonworkplace settings for the socio-economically advantaged and disadvantaged.

\section{Implications for Practice}

For practitioners, particularly public policy makers and Internet service providers, understanding what variables affect post-implementation ICT innovation behavior across groups is critical to effectively planning and implementing interventions like the free Internet TV initiative in LaGrange. This type of project involves considerable resources from many stakeholders. Unsuccessful projects result in a waste of valuable resources, which could discourage the government, residents, and other stakeholders from orchestrating similar initiatives in the future. The integrated set of findings from this research explains why digital inequality interventions (e.g., the LITV initiative) often fail to achieve high levels of success. A policy that focuses not just on reducing or eliminating barriers to technology access but also on complementary aspects that shape behavioral motivations of members within targeted groups to continue to use ICT innovations is essential.

To address digital inequality effectively and economically, we propose a group alignment strategy to replace the typical generic policy that treats everyone as the same and offers a single invariant solution to all populations. This strategy, instead, incorporates the behavioral models of different groups, and configures resources that align with their distinctive needs. This approach might inevitably incur higher administration cost for investigating and understanding the distinctions in behavioral patterns between groups. Nevertheless, with such knowledge, it entails potentially less implementation cost since particular resources would be distributed only to those who need them most. Such a segmentation and alignment strategy, we believe, will lead to a more effective outcome while requiring less total resources.

Based on our analysis of the LaGrange initiative, we believe that providing access to easy-to-use ICT alone-even at no cost-is only part of the solution. The analysis pinpoints other key factors that affect continued ICT use intention (see Figure 2). Understanding these factors and the ones particularly important for the disadvantaged provide points of leverage for policymakers and service providers who wish to address digital inequality and accelerate high-speed Internet usage in the household.

To devise effective interventions, policy-makers need to consider personal network exposure, self-efficacy, hedonic outcome, utilitarian outcomes, PEOU, and availability, as these offer substantial leverage for the socio-economically disadvantaged group (Figure 2). For personal network exposure, one possible avenue to exploit this lever is to establish mechanisms that enable high exposure to aggregate patterns of ICT innovative behavior. It is especially important to create such signaling mechanisms for the disadvantaged, as their social networks are characterized by fewer contacts who are innovative (Putnam 2000). Opinion leaders, community centers, and other sources considered to be credible by the disadvantaged should be effective in relaying information about aggregate patterns of deployment of the innovation.

Furthermore, to boost the disadvantaged's confidence in using ICT, consistent with the self-efficacy literature, interventions can enable them to repeat successful experiences and learn vicariously through others' successful usage, while providing verbal persuasion when appropriate. Admittedly, these approaches may require significant social support. For example, verbal persuasion implies human resources that can provide appropriate oral support and guidance, and vicarious learning implies circumstances or environments in which group learning or social exchange can occur.

Moreover, besides the utilitarian advantages of ICT usage, digital inequality interventions can incorporate services with special emphasis on the entertainment or hedonic aspect of usage to attract the disadvantaged. It is perhaps equally important to infuse an educational element into such services so that the disadvantaged can develop useful skills, rather than just enjoying the technology. In that way, they may apply the skills learned for better life opportunities.

Finally, to address the issue of availability will require significant financial resources. Consequently, partnerships among private and public institutions (e.g., federal and state governments, foundations and philanthropists, and private corporations) with shared interests in addressing digital inequality may be effective to deal with this thorny issue. Of course, it is imperative that initiatives provide ICT that is easy to use for members of the targeted group.

\section{Conclusion}

Drawing upon the perspective of the theory of planned behavior, the present research approaches the digital inequality phenomenon by comparing the post-implementation continued use behavioral models between the socioeconomically advantaged and disadvantaged. This study empirically examined the two groups' models of continued use intention in response to a government initiative that 
offered free high-speed Internet access to every household in a city. The findings reveal significant differences in the behavioral models and identify pivotal factors that shape continued use of ICT by members of each group. This study represents an important step toward developing our theoretical understanding of the digital inequality phenomenon. The results thus provide insights for policymakers to devise effective interventions to achieve planned outcomes.

\section{Acknowledgments}

The authors are grateful for the financial support from the Center for Process Innovation (CEPRIN) at Georgia State University and the Department of Management and Marketing at Hong Kong Polytechnic University (grant \# A-PH38), as well as assistance from the LaGrange city government in data collection. The authors appreciate the guidance on the geographical database by Jimmy McGavick and the valuable inputs provided to us by Charles Jared, Lynette Kvasny, Edward Rigdon, Elena Karahanna, Viswanath Venkatesh, Gordon Davis, and Fred Riggins. The authors would also like to acknowledge the constructive feedback received from the senior editor, associate editor, and reviewers handling this manuscript for MIS Quarterly.

\section{References}

Agarwal, R., and Prasad, J. 1997. “The Role of Innovation Characteristics and Perceived Voluntariness in the Acceptance of Information Technology,” Decision Sciences (28:3), pp. 557-582.

Ajzen, I. 1991. “The Theory of Planned Behavior,” Organizational Behavior and Human Decision Processes (50:2), pp. 179-211.

Ajzen, I., and Madden, T. J. 1986. "Prediction of Goal-Directed Behavior: Attitudes, Intentions, and Perceived Behavioral Control,” Journal of Experimental Social Psychology (22:5), pp. 453-474.

Bandura, A. 1977. "Self-Efficacy: Toward a Unifying Theory of Behavioral Change,” Psychological Review (84:2), pp. 191-215.

Belanger, F., and Van Slyke, C. 2000. "From Employee Shirking to Organizational Learning: The Role of Application Play," Information Technology, Learning and Performance Journal (18:1), pp. 61-70.

Bhattacherjee, A. 2001. "Understanding Information Systems Continuance: An Expectation-Confirmation Model,” MIS Quarterly (25:3), pp. 351-370.

Bishop, A. P., Bazzell, I., Mehra, B., and Smith, C. 2003. “Afya: Social and Digital Technologies That Reach across the Digital Divide,” First Monday (6:4) (retrieved April 17, 2003, from http://www.firstmonday.org/issues/issue6_4/bishop/).

Bobrow, D., and Norman, D. 1975. "Some Principles of Memory Schemata," in Representation and Understanding: Studies in Cognitive Science, D. G. Bobrow and A. Collins (eds.), New York: McGraw-Hill Book Company, pp. 211-236.

Bonfadelli, H. 2002. "The Internet and Knowledge Gaps: A Theoretical and Empirical Investigation,” European Journal of Communication (17:1), pp. 65-84.
Borstein, M. H., and Bradley, R. H. 2003. Socioeconomic Status, Parenting, and Child Development, Mahwah, NJ: Lawrence Erlbaum Associates.

Brown, S., and Venkatesh, V. 2005. "Model of Adoption of Technology in Households: A Baseline Model Test and Extension Incorporating Household Life Cycle,” MIS Quarterly (29:3), pp. 399-426.

Carte, T. A., and Russell, C. 2003. "In Pursuit of Moderation: Nine Common Errors and Their Solutions,” MIS Quarterly (27:3), pp. 479-501.

Checchi, R., Hsieh, J. P.-A., and Straub, D. 2003. "Public IT Policies in Less Developed Countries: A Critical Assessment of the Literature and a Reference Framework for Future Work," Journal of Global Information Technology Management (6:4), pp. 45-64.

Cheung, G. W., and Rensvold, R. B. 2002. "Evaluating Goodnessof-Fit Indexes for Testing Measurement Invariance,” Structural Equation Modeling (9:2), pp. 233-255.

Childers, T. L., and Rao, A. R. 1992. "The Influence of Familial and Peer-Based Reference Groups on Consumer Decisions," Journal of Consumer Research (19:2), pp. 198-211.

Chin, W. W. 1998. "The Partial Least Square Approach to Structural Equation Modeling,” in Modern Methods for Business Research, G. A. Marcoulides (ed.), Mahwah, NJ: Lawrence Erlbaum, pp. 150-170.

Chin, W. W. 2004. "Frequently Asked Questions Partial Least Squares \& PLS-Graph” (available online at http://disc-nt. cba.uh.edu/chin/plsfaq/plsfaq.htm).

Chow, G. C. 1960. "Test of Equality Between Sets of Coefficients in Two Linear Regressions,” Econometrika (28), July, pp. 591-605.

Cocanougher, A. B., and Bruce, G. D. 1971. "Socially Distant Reference Groups and Consumer Aspirations," Journal of Marketing Research (8), pp. 37-381.

Cohen, J., and Cohen, P. 1983. Applied Multiple Regression/ Correlation Analysis for the Behavioral Sciences ( $2^{\text {nd }}$ ed.), Hillsdale, NJ: Lawrence Erlbaum Associates, Inc.

Compeau, D., and Higgins, C. 1995. "Computer Self-Efficacy: Development of a Measure and Initial Test,” MIS Quarterly (19:2), pp. 189-211.

Cortina, J. M. 1993. "Interaction, Nonlinearity, and Multicollinearity: Implications for Multiple-Regression,” Journal of Management (19:4), pp. 915-922.

Crump, B., and Mcllroy, A. 2003. "The Digital Divide: Why the “Don’t-Want-to” Won’t Compute: Lessons from a New Zealand ICT Project,” First Monday (8:12) (retrieved April 17, 2003 from http://www.firstmonday.org/issues/issue8_12/crump/index.html).

Davis, F. D. 1989. "Perceived Usefulness, Perceived Ease of Use and User Acceptance of Information Technology,” MIS Quarterly (13:3), pp. 319-340.

Davis, F. D. 1993. "User Acceptance of Information Technology: System Characteristics, User Perceptions and Behavioral Impacts,” International Journal of Man-Machine Studies (38:3), pp 475-487.

Dais, F. D., Bagozzi, R. P., and Warshaw, P. R. 1989. "User Acceptance of Computer Technology: A Comparison of Two Theoretical Models,” Management Science (35:8), pp. 982-1003. 
Davis, F. D., Bagozzi, R. P., and Warshaw, P. R. 1992. "Extrinsic and Intrinsic Motivation to Use Computers in the Workplace," Journal of Applied Social Psychology (22:14), pp. 1111-1132.

De Haan, J. 2004. “A Multifaced Dynamic Model of the Digital Divide,” IT \& Society (1:7), pp. 66-88.

DiMaggio, P., Hargittai, E., Celeste, C., and Shafer, S. 2004. "From Unequal Access to Differentiated Use: A Literature Review and Agenda for Research on Digital Inequality," in Social Inequality, K. Neckerman (ed.), New York: Russell Sage Foundation.

DiMaggio, P., Hargittai, E., Neuman, W. R., and Robinson, J. P. 2001. "Social Implication of the Internet," Annual Review of Sociology (27:1), pp. 307-336.

Doll, W. J., Hendrickson, A., and Deng, X. 1998. “Using Davis’s Perceived Usefulness and Ease-of-Use Instruments for Decision Making: A Confirmatory and Multigroup Invariance Analysis,” Decision Sciences (29:4), pp. 839-869.

Eastin, M. S., and LaRose, R. 2000. "Internet Self-Efficacy and the Psychology of the Digital Divide," Journal of ComputerMediated Communication (6:1), http://jcmc.indiana.edu/ vol6/issue1/eastin.html.

Fan, A. P., and Eaton, W. W. 2001. "Longitudinal Study Assessing the Joint Effects of Socio-economic Status and Birth Risks on Adult Emotional and Nervous Conditions," British Journal of Psychiatry (178:40), pp. 78-83.

Fligstein, N. 1985. “The Spread of Multidivisional Form among Large Firms,” American Sociological Review (50:3), pp. 377-391.

Fornell, C., and Larcker, D. F. 1981. "Evaluating Structural Equation Models with Unobservable Variables and Measurement Error,” Journal of Marketing Research (18:1), pp. 39-50.

Gefen, D., and Straub, D. 2005. "A Practical Guide to Factorial Validity Using PLS-Graph: Tutorial and Annotated Example,” Communications of the Association for Information Systems (16), pp. 91-109.

Hair, J. F., Anderson, R. E., Tatham, R., and Black, W. C. 1998. Multivariate Data Analysis with Readings (5 ${ }^{\text {th }}$ ed.), New York: Macmillan.

Harbaugh, R. 2002. "Proven Lessons for Generating Good Mail Survey Response Rates,” Medical Marketing \& Media (37:10), pp. 70-75.

Hilgard, E. R., and Bower, G. H. 1975. Theories of Learning, Englewood Cliffs, NJ: Prentice Hall.

Hoffman, D. L., Novak, T. P., and Schlosser, A. E. 2001. "The Evolution of the Digital Divide: Examining the Relationship of Race to Internet Access and Usage over Time,” in The Digital Divide: Facing a Crisis or Creating a Myth?, B. M. Compaine (ed.), Cambridge, MA: MIT Press, pp. 47-97.

Hoffman, L. W. 2003. "Methodological Issues in Studies of SES, Parenting, and Child Development," in Socioeconomic Status, Parenting, and Child Development, M. H. Borstein and R. H. Bradley (eds.), Mahwah, NJ: Lawrence Erlbaum Associates, pp. 125-144.

Holbrook, M. B. 1986. “Aims, Concepts, and Methods for the Representation of Individual Differences in Esthetic Responses to Design Features,” Journal of Consumer Research (13:3), pp. 337-347.
Hong, S., Thong, J., and Tam, K. Y. 2006. "Understanding the Adoption of Multipurpose Information Appliances: The Case of Mobile Data Services," Information Systems Research (17:2), pp. 162-179.

Jackson, L. A., Ervin, K. S., Gardner, P. D., and Schmitt, N. 2001. "The Racial Digital \& Divide: Motivational, Affective, and Cognitive Correlates of Internet Use,” Journal of Applied Social Psychology (31:10), pp. 2019-2046.

Jarvis, C. B., Mackenzie, S. B., and Podsakoff, P. M. 2003. “A Critical Review of Construct Indicators and Measurement Model Misspecification in Marketing and Consumer Research,” Journal of Consumer Research (30:2), pp. 199-218.

Jung, J. Y., Qiu, J. L., and Kim, Y.-C. 2001. "Internet Connectedness and Inequality: Beyond the 'Divide'," Communication Research (28:4), pp. 507-525.

Karahanna, E., Straub, D. W., and Chervany, N. L. 1999. "Information Technology Adoption across Time: A CrossSectional Comparison of Pre-Adoption and Post-Adoption Beliefs,” MIS Quarterly (23:2), pp. 183-213.

Katz, J., and Aspden, P. 1997. "Motivations for and Barriers to Internet Usage: Results of a National Public Opinion Survey," Internet Research: Electronic Networking Applications and Policy (7:3), pp. 170-188.

Keil, M., Meader, G. W., and Kvasny, L. 2003. "Bridging the Digital Divide: The Story of the Free Internet Initiative in LaGrange, Georgia," in Proceedings of the $36^{\text {th }}$ Annual Hawaii International Conference on System Sciences, Los Alamitos, CA: IEEE Computer Society Press, Volume 5, p. 140.2.

Kessler, R. C. 1979. "Stress, Social Status, and Psychological Distress," Journal of Health and Social Behavior (20:3), pp. 259-272.

Kim, S., and Malhotra, N. 2005. "Predicting System Usage from Intention and Past Use: Scale Issues in the Predictors," Decision Sciences (36:1), pp. 187-196.

King, J. L., Gurbaxani, V., Kraemer, K. L., McFarlan, F. W., Raman, K. S., and Yap, C. S. 1994. "Institutional Factors in Information Technology Innovation,” Information Systems Research (5:2), pp. 139-169.

Klapper, J. T. 1960. The Effects of Mass Communication, New York: Free Press.

Krause, N., and Stryker, S. 1984. "Stress and Well-Being: The Buffering Role of Locus of Control Beliefs," Social Science \& Medicine (18:9), pp. 783-790.

Kvasny, L. 2002. Problematizing the Digital Divide: Cultural and Social Reproduction in a Community Technology Initiative, Unpublished Doctoral Dissertation, Georgia State University, Atlanta, GA.

Kvasny, L., and Keil, M. 2002. "The Challenges of Redressing the Digital Divide: A Tale of Two Cities," in Proceedings of the $23^{\text {rd }}$ International Conference on Information Systems, L. Applegate, R. Galliers, and J. I. DeGross (eds.), Barcelona, Spain, December 15-18, pp. 817-828.

Legris, P., Ingham, J., and Collerette, P. 2003. "Why Do People Use Information Technology? A Critical Review of the Technology Acceptance Model,” Information \& Management (40:3), pp. 191-204.

Lenhart, A. 2002. "Barriers to Internet Access: From the Non-user and New User Perspective,” paper presented at the Association 
of Internet Researchers Conference 3.0, Maastricht, Netherlands, October 14.

Li, D., Chau, P., and Lou, H. 2005. "Understanding Individual Adoption of Instant Messaging: An Empirical Investigation,” Journal of the Association for Information Systems (6:4), pp. 102-129.

Liang, H., Saraf, N., Hu, Q., and Xue, Y. 2007. “Assimilation of Enterprise Systems: the Effect of Institutional Pressures and the Mediating Role of Top Management,” MIS Quarterly (31:1), pp. 59-87.

Lou, H., Lou, W., and Strong, D. 2000. "Perceived Critical Mass Effect on Groupware Acceptance,” European Journal of Information Systems (9:2), pp. 91-103.

Lynne, G. D., Casey, C. F., Hodges, A., and Rahmani, M. 1995. "Conservation Technology Adoption Decisions and the Theory of Planned Behavior,” Journal of Economic Psychology (16:4), pp. 581-598.

Lytras, M. D. 2005. “An Interview with Richard Watson,” Official Quarterly Bulletin of AIS Special Interest Group on Semantic Web and Information Systems (2:1), pp. 1-5.

Mathieson, K. 1991. "Predicting User Intentions: Comparing the Technology Acceptance Model with the Theory of Planned Behavior,” Information Systems Research (2:3), pp. 173-191.

Mayer, K., and Buckley, W. 1970. Class and Society, New York: Random House.

Meader, G. W., Keil, M., and McFarlan, W. 2002. "The Free Internet Initiative in LaGrange, Georgia,” Boston: Harvard Business School Publishing Division, Case \#0-302-041.

Microsoft. 2006. "Project Shiksha: Empowering the Future," http://www.microsoft.com/india/education/pil/shiksha/.

National Public Radio. 2000. "Morning Edition, Suanna Capeluto," August 22 (accessed on March 23, 2003, http://www.npr.org/ templates/story/story.php?storyId=1080995).

NTIA. 1998. "Falling Through the Net II: New Data on the Digital Divide," National Telecommunications and Information Administration, U.S. Department of Commerce (retrieved April 17, 2003, http://www.ntia. doc.gov/ntiahome/digitaldivide).

NTIA. 1999. "Defining the Digital Divide,” National Telecommunications and Information Administration, U.S. Department of Commerce (retrieved April 17, 2003, http://www.ntia.doc.gov/ ntiahome/fttn99/contents.html).

NTIA. 2000. "Falling Through the Net: Toward Digital Inclusion, A Report on Americans' Access to Technology Tools,” National Telecommunications and Information Administration, U.S. Department of Commerce (retrieved April 17, 2003, http:// ww.ntia.doc.gov/ntiahome/digitaldivide).

NTIA. 2002. "A Nation Online: How Americans are Expanding Their Use of the Internet," National Telecommunications and Information Administration, U.S. Department of Commerce (retrieved April 17, 2003, http://www.ntia.doc.gov/ntiahome/dn/ nationonline_020502.html).

Norris, P. 2001. Digital Divide: Civic Engagement, Information Poverty and the Internet Worldwide, Cambridge, UK: Cambridge University Press.

Nunnally, J. C., and Bernstein, I. H. 1994. Psychometric Theory ( $3^{\text {rd }}$ ed.), New York: McGraw-Hill.

OECD. "Understanding the Digital Divide," Organisation for Economic Co-Operation and Development (retrieved April 17, 2003, http://www.oecd.org/dataoecd/38/57/1888451.pdf).
Palmer, D. A., Jennings, P. D., and Zhou, X. 1993. "Late Adoption of the Multidivisional Form by Large U.S. Corporations: Institutional, Political, and Economic Accounts,” Administrative Science Quarterly (38:1), pp. 100-131.

Pavlou, P. A., and Fygenson, M. 2006. "Understanding and Predicting Electronic Commerce Adoption: An Extension of the Theory of Planned Behavior," MIS Quarterly (30:1), pp. 115-143.

Parker, J., and Endler, N. 1996. "Coping and Defense: A Historical Overview," in Handbook of Coping. Theory, Research, Applications, M. Zeidner and N. Endler (eds.), New York: John Wiley \& Sons, pp. 3-23.

Payton, F. 2003. "Rethinking the Digital Divide,” Communications of the ACM (46:6), pp. 89-91.

Pearlin, L., and Schooler, C. 1978. "The Structure of Coping," Journal of Health and Social Behavior (19:1), pp. 2-21.

Pinsonneault, A., and Kraemer, K. L. 1993. "Survey Research Methodology in Management Information Systems: An Assessment,” Journal of Management Information Systems (10:2), pp. 75-105.

Podsakoff, P. M., MacKenzie, S. B., Lee, J.-Y., and Podsakoff, N. P. 2003. "Common Method Biases in Behavioral Research: A Critical Review of the Literature and Recommended Remedies," Journal of Applied Psychology (88:5), pp. 879-903.

Podsakoff, P. M., and Organ, D. W. 1986. "Self Reports in Organizational Research: Problems and Prospects," Journal of Management (12:4), pp. 531-544.

Pratt, L. 1971. "The Relationship of Socioeconomic Status on Health,” American Journal of Public Health (61:2), pp. 281-291.

Prensky, M. 2004. Digital Game-Based Learning, New York: McGraw-Hill.

Putnam, R. D. 2000. Bowling Alone: The Collapse and Revival of American Community, New York: Simon \& Schuster.

Ravichandran, T., and Rai, A. 2000. "Quality Management in System Development: An Organizational System Perspective,” MIS Quarterly (24:3), pp. 381-415.

Rogers, E. M. 2003. Diffusion of Innovation ( $5^{\text {th }}$ ed.), New York: Free Press.

Rozeboom, W. W. 1979. "Sensitivity of a Linear Composite Predictor Items to Differential Item Weighting,” Psychometrica (44:3), pp. 289-296.

Schwarzer, R., and Jerusalem, M. 1995. “Optimistic Self-Beliefs as a Resources Factor in Coping with Stress,” in Extreme Stress and Communities: Impact and Intervention, S. E. Hobfoll and M. W. deVries (eds.), Dordrecht, The Netherlands: Kluwer Academic Publishers, pp. 159-177.

Shah, D. V., Kwak, N., and Holbert, R. L. 2001. “Connecting and Disconnecting with Civic Life: Patterns of Internet Use and the Production of Social Capital,” Political Communication (18), pp. 141-162

Sharma, S., Durand, R., and Gur-Arie, O. 1981. "Identification and Analysis of Moderator Variables,” Journal of Marketing Research (18), 1981, pp. 291-299.

Sheppard, B., Hartwick, J., and Warshaw, P. 1988. “The Theory of Reasoned Action: A Meta-Analysis of Past Research with Recommendations for Modifications and Future Research,” Journal of Consumer Research (15:3), pp. 325-343. 
Steeh, C. G. 1981. "Trends in Nonresponse Rates, 1952-1979," Public Opinion Quarterly (45:1), pp. 40-47.

Steenkamp, J., and Baumgartner, H. 1998. “Assessing Measurement Invariance in Cross-National Consumer Research,” Journal of Consumer Research (25:1), pp. 78-90.

Szajna, B. 1996. "Empirical Evaluation of the Revised Technology Acceptance Model,” Management Science (42:1), pp. 85-92.

Taylor, S., and Todd, P. 1995a. "Assessing IT Usage: The Role of Prior Experience,” MIS Quarterly (19:4), pp. 561-570.

Taylor, S., and Todd, P. A. 1995b. "Understanding Information Technology Usage: A Test of Competing Models,” Information Systems Research (6:2), pp. 144-176.

Triandis, H. C. 1971. Attitude and Attitude Change, New York: John Wiley and Sons.

U.S. Advisory Council on the National Information Infrastructure. "America on the Information Superhighway," 1996 (retrieved April 17, 2003, http://www.benton.org/publibrary/kickstart/ nation.america.html).

Valente, T. 1995. Network Models of the Diffusion of Innovations, New York: Hampton Press.

Van der Heijden, H. 2004. "User Acceptance of Hedonic Information Systems,” MIS Quarterly (28:4), pp. 695-704.

Van Dijk, J., and Hacker, K. 2003. "The Digital Divide as a Complex and Dynamic Phenomenon,” The Information Society (19:4), pp. 315-326.

Van der Meer, A., and Van Winden, W. 2003. “E-Governance in Cities: A Comparison of Urban Information and Communication Technology Policies,” Regional Studies (37:4), pp. 407-419.

Van Winden, W. 2001. "The End of Social Exclusion? On Information Technology Policy as a Key to Social Inclusion in Large European Cities,” Regional Studies (35:9), pp. 861-877.

Venkatesh, V. 1999. "Creation of Favorable User Perceptions: Exploring the Role of Intrinsic Motivation,” MIS Quarterly (23:2), pp. 239-260.

Venkatesh, V. 2000. “Determinants of Perceived Ease of Use: Integration Control, Intrinsic Motivation and Emotion into the Technology Acceptance Model,” Information Systems Research (11:4), pp. 342-365.

Venkatesh, V., and Brown, S. A. 2001. “A Longitudinal Investigation of Personal Computers in Homes: Adoption Determinants and Emerging Challenges,” MIS Quarterly (25:1), pp. 71-102.

Venkatesh, V., and Davis, F. D. 2000. “A Theoretical Extension of the Technology Acceptance Model: Four Longitudinal Field Studies,” Management Science (46:2), pp. 186-204.

Venkatesh, V., and Morris, M. G. 2000. "Why Don’t Men Ever Stop to Ask for Directions? Gender, Social Influence, and Their Role in Technology Acceptance and Usage Behavior,” MIS Quarterly (24:1), pp. 115-139.

Venkatraman, M. P., and MacInnis, D. J. 1985. “The Epistemic and Sensory Exploratory Behaviors of Hedonic and Cognitive Consumers," Advances in Consumer Research (12:1), pp. 102-107.

Venkatraman, M. P., and Price, L. L. 1990. "Differentiating between Cognitive and Sensory Innovativeness: Concepts, Measurement, and Implications," Journal of Business Research (20:4), pp. 293-315.
Wheaton, B. 1985. "Personal Resources and Mental Health: Can There Be Too Much of a Good Thing?," in Research in Community and Mental Health, J. R. Greenley (ed.), Greenwich, CT: JAI Press, pp. 139-184.

Williams, D. R. 1990. "Socioeconomic Differentials in Health: A Review and Redirection,” Social Psychology Quarterly (53:2), pp. 81-99.

\section{About the Authors}

J. J. Po-An Hsieh is currently an assistant professor of MIS in the Department of Management and Marketing at Hong Kong Polytechnic University. He received his Ph.D. in CIS from Georgia State University, a dual MBA/M.S. degree from University of Maryland, and a B.S. in industrial engineering from National Tsing Hua University. His research focuses on the areas of digital divide/ digital inequality, ICT policy, and IS usage. He has published in the European Journal of Information Systems and Journal of Global Information Technology Management, as well as having presented papers at the International Conference on Information Systems, the Academy of Management Meeting, the Digital Divide Symposium, and other conferences.

Arun Rai is Regents' Professor and the Harkins Chair in the Center for Process Innovation and the Department of Computer Information Systems at Georgia State University. His research has been published in Decision Sciences, European Journal of Operations Research, IEEE Transactions on Engineering Management, Information Systems Research, Journal of Management Information Systems, MIS Quarterly, and other journals. He serves as senior editor for Information Systems Research, and as associate senior for Management Science. He has also served as senior editor for the Journal of Strategic Information Systems and on the editorial boards for Decision Sciences, IEEE Transactions on Engineering Management, Information Systems Research, Journal of the AIS, MIS Quarterly, and others. His research has been sponsored by leading corporations, including A. T. Kearney, Bozell Worldwide, DaimlerChrysler, Gartner, IBM, Intel, UPS, and SAP.

Mark Keil is the Board of Advisors Professor of Computer Information Systems at Georgia State University. His research focuses on software project management and has been published in MIS Quarterly, Decision Sciences, Sloan Management Review, Journal of Management Information Systems, IEEE Transactions on Engineering Management, and other journals. He currently serves on the editorial boards of Decision Sciences and the Journal of Management Information Systems. He has also served on the editorial board of IEEE Transactions on Engineering Management, as an associate editor for MIS Quarterly, and as co-editor of The DATA BASE for Advances in Information Systems. He earned his bachelor's degree from Princeton University, his master's degree from MIT's Sloan School of Management, and his doctorate in management information systems from the Harvard Business School. 


\section{Appendix A}

\section{Item-Factor Loadings and Sample Cross-Loadings}

\begin{tabular}{|c|c|c|c|c|c|c|c|c|c|c|c|c|c|}
\hline $\begin{array}{c}\text { SED } \\
\text { Group } \\
\text { Item } \\
\text { Loading }\end{array}$ & ATT & UO & HO & SN & FRPF & GII & PBC & SE & PEOU & Avail & PNE & U_Int & $\begin{array}{c}\text { SEA } \\
\text { Group } \\
\text { Item } \\
\text { Loading }\end{array}$ \\
\hline ATT1 & 0.99 & 0.72 & 0.76 & 0.46 & 0.51 & 0.35 & 0.27 & 0.39 & 0.49 & -0.15 & 0.31 & 0.47 & 0.98 \\
\hline ATT2 & 0.99 & 0.73 & 0.78 & 0.46 & 0.51 & 0.33 & 0.28 & 0.39 & 0.51 & -0.15 & 0.32 & 0.46 & 0.99 \\
\hline ATT3 & 0.99 & 0.78 & 0.78 & 0.42 & 0.48 & 0.30 & 0.32 & 0.44 & 0.54 & -0.12 & 0.33 & 0.46 & 0.97 \\
\hline U01 & 0.72 & 0.98 & 0.67 & 0.53 & 0.56 & 0.36 & 0.22 & 0.37 & 0.49 & -0.09 & 0.31 & 0.49 & 0.99 \\
\hline UO2 & 0.71 & 0.98 & 0.68 & 0.55 & 0.58 & 0.39 & 0.22 & 0.34 & 0.46 & -0.06 & 0.31 & 0.51 & 0.99 \\
\hline UO3 & 0.74 & 0.96 & 0.70 & 0.55 & 0.59 & 0.40 & 0.24 & 0.37 & 0.48 & -0.06 & 0.32 & 0.52 & 0.98 \\
\hline UO4 & 0.78 & 0.98 & 0.65 & 0.51 & 0.55 & 0.36 & 0.27 & 0.40 & 0.52 & -0.06 & 0.30 & 0.49 & 0.98 \\
\hline HO1 & 0.75 & 0.69 & 0.99 & 0.51 & 0.56 & 0.40 & 0.24 & 0.39 & 0.50 & -0.03 & 0.38 & 0.51 & 0.99 \\
\hline $\mathrm{HO2}$ & 0.73 & 0.70 & 0.99 & 0.52 & 0.57 & 0.41 & 0.25 & 0.41 & 0.52 & -0.02 & 0.36 & 0.51 & 0.99 \\
\hline $\mathrm{HO}$ & 0.73 & 0.70 & 0.99 & 0.51 & 0.56 & 0.43 & 0.27 & 0.42 & 0.51 & -0.02 & 0.36 & 0.50 & 0.99 \\
\hline SN1 & 0.44 & 0.55 & 0.51 & 0.98 & 0.78 & 0.57 & 0.08 & 0.16 & 0.23 & 0.07 & 0.37 & 0.36 & 0.98 \\
\hline SN2 & 0.44 & 0.52 & 0.50 & 0.98 & 0.77 & 0.57 & 0.00 & 0.11 & 0.20 & 0.11 & 0.35 & 0.30 & 0.98 \\
\hline FRPF* $^{*}$ & 0.49 & 0.57 & 0.55 & 0.72 & 1.00 & 0.63 & 0.03 & 0.17 & 0.23 & 0.15 & 0.37 & 0.33 & 1 \\
\hline Gov1 & 0.31 & 0.38 & 0.40 & 0.59 & 0.65 & 0.97 & 0.07 & 0.10 & 0.10 & 0.21 & 0.21 & 0.18 & 0.97 \\
\hline Gov2 & 0.33 & 0.37 & 0.40 & 0.54 & 0.61 & 0.96 & 0.10 & 0.14 & 0.18 & 0.17 & 0.18 & 0.20 & 0.97 \\
\hline PBC1 & 0.27 & 0.24 & 0.25 & 0.06 & 0.02 & 0.07 & 0.94 & 0.71 & 0.64 & -0.11 & 0.18 & 0.36 & 0.94 \\
\hline PBC2 & 0.32 & 0.26 & 0.27 & 0.05 & 0.04 & 0.07 & 0.97 & 0.74 & 0.69 & -0.13 & 0.17 & 0.39 & 0.95 \\
\hline PBC3 & 0.21 & 0.18 & 0.18 & -0.01 & 0.03 & 0.11 & 0.86 & 0.65 & 0.53 & -0.03 & 0.04 & 0.30 & 0.91 \\
\hline SE1 & 0.37 & 0.35 & 0.34 & 0.13 & 0.14 & 0.12 & 0.71 & 0.97 & 0.69 & -0.05 & 0.18 & 0.51 & 0.96 \\
\hline SE2 & 0.41 & 0.38 & 0.44 & 0.15 & 0.19 & 0.10 & 0.71 & 0.96 & 0.70 & -0.02 & 0.18 & 0.53 & 0.95 \\
\hline SE3 & 0.40 & 0.36 & 0.38 & 0.13 & 0.18 & 0.12 & 0.70 & 0.95 & 0.69 & -0.02 & 0.17 & 0.50 & 0.96 \\
\hline PEOU_1 & 0.42 & 0.37 & 0.41 & 0.11 & 0.15 & 0.07 & 0.73 & 0.73 & 0.93 & -0.03 & 0.18 & 0.41 & 0.93 \\
\hline PEOU_2 & 0.39 & 0.39 & 0.37 & 0.14 & 0.16 & 0.09 & 0.61 & 0.64 & 0.92 & -0.05 & 0.25 & 0.33 & 0.91 \\
\hline PEOU_3 & 0.58 & 0.55 & 0.58 & 0.25 & 0.28 & 0.18 & 0.57 & 0.69 & 0.93 & -0.08 & 0.28 & 0.41 & 0.88 \\
\hline PEOU_4 & 0.52 & 0.54 & 0.52 & 0.35 & 0.30 & 0.19 & 0.53 & 0.57 & 0.84 & -0.05 & 0.25 & 0.40 & 0.81 \\
\hline Avail_1 & -0.21 & -0.14 & -0.12 & -0.02 & 0.04 & 0.15 & -0.10 & -0.05 & -0.09 & 0.91 & -0.11 & -0.13 & 0.95 \\
\hline Avail_2 & 0.02 & 0.08 & 0.15 & 0.23 & 0.26 & 0.20 & -0.06 & 0.02 & 0.02 & 0.86 & 0.11 & 0.12 & 0.82 \\
\hline PNE & 0.32 & 0.32 & 0.37 & 0.37 & 0.38 & 0.20 & 0.14 & 0.19 & 0.26 & -0.03 & 1.00 & 0.40 & 1 \\
\hline U_Int_1 & 0.47 & 0.50 & 0.51 & 0.35 & 0.34 & 0.20 & 0.37 & 0.52 & 0.40 & -0.05 & 0.40 & 0.99 & 0.98 \\
\hline U_Int_2 & 0.45 & 0.50 & 0.47 & 0.33 & 0.32 & 0.17 & 0.39 & 0.55 & 0.45 & -0.07 & 0.38 & 0.97 & 0.99 \\
\hline U_Int_3 & 0.45 & 0.51 & 0.51 & 0.32 & 0.35 & 0.20 & 0.34 & 0.50 & 0.39 & 0.01 & 0.38 & 0.97 & 0.97 \\
\hline
\end{tabular}

PLS item cross-loadings were calculated according to the procedure suggested by Gefen and Straub (2005). While the cross-loadings for ATT, $\mathrm{UO}$, and $\mathrm{HO}$ are relatively high, the differences between loadings on principal factors and on other constructs are higher than the threshold suggested by Gefen and Straub. In fact, only 6 out of the 372 cross-loading differences are between 0.1 and 0.2 ; all other cross-loading differences are higher than 0.2 .

${ }^{*} \mathrm{FRPF}$ is a formative construct, whose index score is computed as a unit mean of four items. 


\section{Appendix B}

\section{Squared Pairwise Correlations and Assessment of Discriminant Validity}

\begin{tabular}{|c|c|c|c|c|c|c|c|c|c|c|c|c|}
\hline & ATT & UO & HO & SN & FPRF & $\begin{array}{l}\text { Gov. } \\
\text { Inf. }\end{array}$ & PBC & $\begin{array}{c}\text { Self- } \\
\text { Efficacy }\end{array}$ & PEOU & $\begin{array}{l}\text { Avail- } \\
\text { ability }\end{array}$ & PNE & Intention \\
\hline ATT & 0.98 & & & & & & & & & & & \\
\hline UO & 0.73 & 0.95 & & & & & & & & & & \\
\hline $\mathrm{HO}$ & 0.69 & 0.64 & 0.98 & & & & & & & & & \\
\hline $\mathrm{SN}$ & 0.20 & 0.30 & 0.26 & 0.96 & & & & & & & & \\
\hline FPRF & 0.26 & 0.34 & 0.32 & 0.75 & $\mathrm{~N} / \mathrm{A}$ & & & & & & & \\
\hline Gov. Inf. & 0.11 & 0.15 & 0.17 & 0.34 & 0.43 & 0.93 & & & & & & \\
\hline PBC & 0.09 & 0.06 & 0.06 & 0.00 & 0.00 & 0.01 & 0.85 & & & & & \\
\hline $\begin{array}{l}\text { Self- } \\
\text { efficacy }\end{array}$ & 0.17 & 0.14 & 0.17 & 0.02 & 0.03 & 0.01 & 0.60 & 0.92 & & & & \\
\hline PEOU & 0.27 & 0.25 & 0.26 & 0.05 & 0.05 & 0.02 & 0.44 & 0.54 & 0.82 & & & \\
\hline Availability & 0.02 & 0.00 & 0.00 & 0.01 & 0.03 & 0.04 & 0.13 & 0.00 & 0.00 & 0.82 & & \\
\hline PNE & 0.11 & 0.10 & 0.14 & 0.14 & 0.15 & 0.04 & 0.02 & 0.03 & 0.07 & 0.00 & $\mathrm{~N} / \mathrm{A}$ & \\
\hline Intention & 0.22 & 0.26 & 0.26 & 0.10 & 0.12 & 0.04 & 0.14 & 0.29 & 0.18 & 0.00 & 0.16 & 0.95 \\
\hline
\end{tabular}

B2. Advantaged Group

\begin{tabular}{|c|c|c|c|c|c|c|c|c|c|c|c|c|}
\hline & ATT & UO & $\mathrm{HO}$ & SN & FPRF & $\begin{array}{c}\text { Gov. } \\
\text { Inf. }\end{array}$ & PBC & $\begin{array}{c}\text { Self- } \\
\text { Efficacy }\end{array}$ & PEOU & $\begin{array}{l}\text { Avail- } \\
\text { ability }\end{array}$ & PNE & Intention \\
\hline ATT & 0.96 & & & & & & & & & & & \\
\hline UO & 0.64 & 0.97 & & & & & & & & & & \\
\hline $\mathrm{HO}$ & 0.60 & 0.76 & 0.97 & & & & & & & & & \\
\hline SN & 0.29 & 0.34 & 0.31 & 0.96 & & & & & & & & \\
\hline FPRF & 0.33 & 0.39 & 0.33 & 0.79 & N/A & & & & & & & \\
\hline Gov. Inf. & 0.12 & 0.13 & 0.12 & 0.27 & 0.29 & 0.94 & & & & & & \\
\hline PBC & 0.04 & 0.02 & 0.02 & 0.00 & 0.00 & 0.02 & 0.87 & & & & & \\
\hline $\begin{array}{l}\text { Self- } \\
\text { Efficacy }\end{array}$ & 0.09 & 0.06 & 0.08 & 0.00 & 0.01 & 0.01 & 0.40 & 0.92 & & & & \\
\hline PEOU & 0.19 & 0.18 & 0.20 & 0.03 & 0.05 & 0.03 & 0.28 & 0.52 & 0.78 & & & \\
\hline Availability & 0.00 & 0.00 & 0.00 & 0.00 & 0.00 & 0.01 & 0.00 & 0.00 & 0.00 & 0.79 & & \\
\hline PNE & 0.27 & 0.28 & 0.29 & 0.25 & 0.31 & 0.08 & 0.03 & 0.07 & 0.15 & 0.01 & $\mathrm{~N} / \mathrm{A}$ & \\
\hline Intention & 0.38 & 0.43 & 0.43 & 0.26 & 0.30 & 0.08 & 0.02 & 0.08 & 0.17 & 0.01 & 0.35 & 0.96 \\
\hline
\end{tabular}

Note: AVE of every multi-item construct is shown on the main diagonal. (Personal Network Exposure (PNE) is a single-item construct.) Squared correlations are off the diagonal. 


\section{Appendix C}

\section{Measurement Items for Key Constructs}

\begin{tabular}{|c|c|c|c|}
\hline Construct & \multicolumn{2}{|c|}{ Items } & $\begin{array}{l}\text { Sources That Inform } \\
\text { the Construct }\end{array}$ \\
\hline Attitude & \multicolumn{2}{|l|}{$\begin{array}{l}\text { All things considered, using the Internet TV is } \\
\text { 1. extremely negative ...extremely positive } \\
\text { 2. extremely bad...extremely god } \\
\text { 3. extremely harmful ....extremely helpful }\end{array}$} & $\begin{array}{l}\text { Ajzen } 1991 \\
\text { Ajzen and Madden } 1986\end{array}$ \\
\hline $\begin{array}{l}\text { Utilitarian } \\
\text { Outcomes }\end{array}$ & \multicolumn{2}{|c|}{$\begin{array}{l}\text { Using the Internet TV } \\
\text { 1. improves my performance for communication \& information search. } \\
\text { 2. improves my productivity for communication \& information search. } \\
\text { 3. enhances my effectiveness for communication \& information search. } \\
\text { 4. is useful for my communication \& information search. }\end{array}$} & $\begin{array}{l}\text { Davis } 1989 \\
\text { Rogers } 2003 \\
\text { Venkatesh and Brown } 2001\end{array}$ \\
\hline $\begin{array}{l}\text { Hedonic } \\
\text { Outcomes }\end{array}$ & \multicolumn{2}{|c|}{$\begin{array}{l}\text { Using the Internet TV } \\
1 . \quad \text { is enjoyable. } \\
2 . \quad \text { is pleasant. } \\
3 . \quad \text { is fun. }\end{array}$} & $\begin{array}{l}\text { Davis } 1989 \\
\text { Venkatesh } 1999 \\
\text { Venkatesh and Brown } 2001\end{array}$ \\
\hline $\begin{array}{l}\text { Subjective } \\
\text { Norms (SN) }\end{array}$ & \multicolumn{2}{|c|}{$\begin{array}{l}\text { (Strongly Disagree/Agree ) (1-7 scale) } \\
\text { 1. People who influence me think that I should use the Internet TV. } \\
\text { 2. People who are important to me think that I should use the Internet TV. }\end{array}$} & $\begin{array}{l}\text { Ajzen } 1991 \\
\text { Ajzen and Madden } 1986\end{array}$ \\
\hline $\begin{array}{l}\text { Family, } \\
\text { Relatives, } \\
\text { Friends, and } \\
\text { Peers' } \\
\text { Influence }\end{array}$ & \multicolumn{2}{|c|}{$\begin{array}{l}\text { (Strongly Disagree/Agree ) (1-7 scale) } \\
\text { 1. My family thinks that I should use the Internet TV. } \\
\text { 1. My relatives think that I should use the Internet TV. } \\
\text { 3. My friends think that I should use the Internet TV. } \\
\text { 4. People I work with think that I should use the Internet TV }\end{array}$} & $\begin{array}{l}\text { Karahanna et al. } 1999 \\
\text { Taylor and Todd } 1995 \mathrm{~b} \\
\text { Venkatesh and Brown } 2001\end{array}$ \\
\hline $\begin{array}{l}\text { Government } \\
\text { Institutions' } \\
\text { Expectation }\end{array}$ & \multicolumn{2}{|c|}{$\begin{array}{l}\text { (Strongly Disagree/Agree ) (1-7 scale) } \\
\text { 1. The city government expects me to use the Internet TV. } \\
\text { 2. The city government thinks that I should use the Internet TV }\end{array}$} & $\begin{array}{l}\text { Karahanna et al. } 1999 \\
\text { Lynne et al. } 1995\end{array}$ \\
\hline $\begin{array}{l}\text { Perceived } \\
\text { Behavioral } \\
\text { Control } \\
(\text { PBC) }\end{array}$ & \multicolumn{2}{|c|}{$\begin{array}{l}\text { (Strongly Disagree/Agree ) (1-7 scale) } \\
\text { 1. I have the resources, knowledge, and ability to use the Internet TV. } \\
\text { 2. I can use the Internet TV. } \\
\text { 3. Using the Internet TV is entirely within my control. }\end{array}$} & $\begin{array}{l}\text { Ajzen } 1991 \\
\text { Ajzen and Madden } 1986\end{array}$ \\
\hline Self-Efficacy & \multicolumn{2}{|c|}{$\begin{array}{l}\text { (Strongly Disagree/Agree ) (1-7 scale) } \\
\text { 1. I feel comfortable using the Internet TV on my own. } \\
\text { 2. I can easily operate the Internet TV on my own. } \\
\text { 3. I feel comfortable using the Internet TV even if there is no one around me to tell me } \\
\text { how to use it. }\end{array}$} & $\begin{array}{l}\text { Bandura } 1977 \\
\text { Compeau and Higgins } 1995\end{array}$ \\
\hline $\begin{array}{l}\text { Perceived } \\
\text { Ease of Use }\end{array}$ & \multicolumn{2}{|c|}{$\begin{array}{l}\text { (Strongly Disagree/Agree ) (1-7 scale) } \\
\text { 1. My interaction with the Internet TV is clear and understandable. } \\
\text { 2. Interacting with the Internet TV does not require a lot of my mental effort. } \\
\text { 3. I find the Internet TV easy to use. } \\
\text { 4. I find it easy to get the Internet TV to do what I want it to do. }\end{array}$} & $\begin{array}{l}\text { Davis } 1989 \\
\text { Davis et al. } 1989\end{array}$ \\
\hline Availability & \multicolumn{2}{|c|}{$\begin{array}{l}\text { (Strongly Disagree/Agree ) (1-7 scale) } \\
\text { 1. It is difficult for me to use the Internet TV when other members in my household want } \\
\text { to watch TV. } \\
\text { 2. Many people in my household want to use Internet TV, and I don't always get to use it. }\end{array}$} & $\begin{array}{l}\text { Kvasny and Keil } 2002 \\
\text { Meader et al. } 2002 \\
\text { Taylor and Todd } 1995 \mathrm{~b}\end{array}$ \\
\hline $\begin{array}{l}\text { Personal } \\
\text { Network } \\
\text { Exposure }\end{array}$ & \multicolumn{2}{|c|}{ 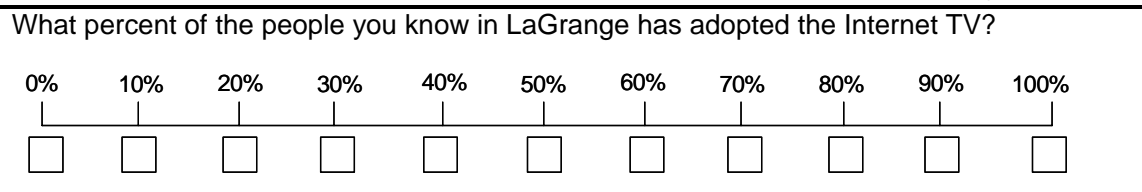 } & $\begin{array}{l}\text { Fligstein } 1985 \\
\text { Palmer et al. } 1993 \\
\text { Valente } 1995\end{array}$ \\
\hline $\begin{array}{l}\text { Behavioral } \\
\text { Intention for } \\
\text { Continued } \\
\text { Use }\end{array}$ & \multicolumn{2}{|c|}{$\begin{array}{l}\text { I intend to continue using the Internet TV } \\
\text { 1. during the next three months. } \\
\text { 2. for email, browsing, or searching during the next three months. } \\
\text { 3. frequently during the next three months. }\end{array}$} & $\begin{array}{l}\text { Ajzen } 1991 \\
\text { Ajzen and Madden } 1986\end{array}$ \\
\hline
\end{tabular}




\section{Appendix D}

\section{Supplemental Measurement Invariance Analysis for Group Comparson}

To further evaluate the appropriateness to compare path coefficients between the two groups, we applied multigroup measurement invariance analysis (Doll et al. 1998; Steenkamp and Baumgartner 1998). Using AMOS 5.0, we performed configural and metric invariance analyses to evaluate if the measurement models are invariant across the advantaged and disadvantaged groups. Configural invariance denotes that the patterns of item loadings are congeneric across groups (Doll et al. 1998; Steenkamp and Baumgartner 1998). No restrictions are imposed on metrics across groups when modeling configural invariance (Doll et al. 1998). Next, metric invariance checks whether items have equal loadings between groups. Item loadings are constrained to be equivalent across groups when modeling metric invariance. If the change in CFI between these two nested (configural and metric) models is smaller than the suggested threshold 0.01 (Cheung and Rensvold 2002), then metric invariance is supported, permitting path coefficient comparison between groups.

We applied the analytical procedure described above to assess measurement invariance across the advantaged and disadvantaged groups. Due to sample size and model complexity constraints, we performed this analysis separately for each block of the research model. Configural invariance analysis revealed the pattern of item loadings to be congeneric across the two groups. In terms of metric invariance, the changes in CFI for block 1, 2, 3, and 4 were $0.002,0.001,0.001$, and 0.002 respectively for each of their nested models. Given that these values were all lower than the recommended 0.01 level (Cheung and Rensvold 2002), metric invariance is established, providing additional support for meaningful path coefficient comparison across groups. 


\section{Appendix E}

\section{Common Method Bias Analysis}

\begin{tabular}{|c|c|c|c|c|}
\hline Item & $\begin{array}{c}\text { Substantive Factor } \\
\text { Loading (R1) }\end{array}$ & $\mathbf{R}^{2}$ & $\begin{array}{c}\text { Common Method } \\
\text { Factor Loading (R2) }\end{array}$ & $\mathbf{R}^{2}$ \\
\hline Attitude (item_1) & 0.981 ** & 0.962 & 0.062 & 0.004 \\
\hline Attitude (item_2) & 0.978 ** & 0.956 & -0.012 & 0.000 \\
\hline Attitude (item_3) & 0.985 ** & 0.970 & -0.051 & 0.003 \\
\hline SN (item_1) & 0.999 ** & 0.998 & 0.018 & 0.000 \\
\hline SN (item_2) & 0.972 ** & 0.945 & -0.019 & 0.000 \\
\hline PBC (item_1) & 0.946 ** & 0.895 & -0.031 & 0.001 \\
\hline PBC (item_2) & 0.953 ** & 0.908 & 0.002 & 0.000 \\
\hline PBC (item_3) & $0.885 * *$ & 0.783 & 0.034 & 0.001 \\
\hline Utilitarian Outcomes (item_1) & 0.992 ** & 0.984 & -0.008 & 0.000 \\
\hline Utilitarian Outcomes (item_2) & 0.991 ** & 0.982 & -0.035 & 0.001 \\
\hline Utilitarian Outcomes (item_3) & 0.880 ** & 0.774 & 0.000 & 0.000 \\
\hline Utilitarian Outcomes (item_4) & 0.976 ** & 0.953 & 0.044 & 0.002 \\
\hline Hedonic Outcomes (item_1) & 0.993 ** & 0.986 & 0.000 & 0.000 \\
\hline Hedonic Outcomes (item_2) & 0.976 ** & 0.953 & 0.018 & 0.000 \\
\hline Hedonic Outcomes (item_3) & 0.991 ** & 0.982 & -0.018 & 0.000 \\
\hline FRPF (item_1) & 0.973 ** & 0.947 & 0.016 & 0.000 \\
\hline Gov. Institutions' Influence (item_1) & 0.973 ** & 0.947 & -0.003 & 0.000 \\
\hline Gov. Institutions' Influence (item_2) & 0.969 ** & 0.939 & 0.003 & 0.000 \\
\hline Self-Efficacy (Item_1) & 0.952 ** & 0.906 & 0.013 & 0.000 \\
\hline Self-Efficacy (item_2) & 0.952 ** & 0.906 & 0.010 & 0.000 \\
\hline Self-Efficacy (item_3) & 0.968 ** & 0.937 & -0.023 & 0.001 \\
\hline PEOU (item_1) & 0.939 ** & 0.882 & -0.016 & 0.000 \\
\hline PEOU (item_2) & 0.925 ** & 0.856 & 0.081 & 0.007 \\
\hline PEOU (item_3) & 0.913 ** & 0.834 & 0.086 & 0.007 \\
\hline PEOU (item_4) & 0.854 ** & 0.729 & 0.160 ** & 0.026 \\
\hline Availability (item_1) & 0.811 ** & 0.658 & $0.170 * *$ & 0.026 \\
\hline Availability (item_2) & 0.788 ** & 0.621 & -0.182 ** & 0.029 \\
\hline Personal Network Exposure (item_1) & 1.000 ** & 1.000 & 0.000 & 0.000 \\
\hline Intention for Continued Use (item_1) & 0.993 ** & 0.986 & -0.006 & 0.000 \\
\hline Intention for Continued Use (item_2) & 0.989 ** & 0.978 & -0.011 & 0.000 \\
\hline Intention for Continued Use (item_3) & 0.961 ** & 0.924 & 0.017 & 0.000 \\
\hline Average & 0.950 & 0.906 & 0.010 & 0.003 \\
\hline
\end{tabular}




\section{Appendix F}

\section{Supplementary Analysis on Type of Moderation of Socio-Economic Status}

Results of the PLS analysis support the moderation effect of socio-economic status (SES) on some of the hypothesized relationships. To further investigate the type of moderation of SES (i.e., pure moderator, quasi-moderator, or homologizer) and to examine if the detected moderation was not an artifact of unequal measurement error across the subsample (i.e., homologizer), we followed the MRA procedure recommended by Sharma et al. (1981). Additionally, we examined if the conclusion regarding the type of moderation is sensitive to nonlinear effects of the predictors on the criterion. These additional analyses validate our conceptualization of SES as moderating the strength of the relationships between the identified criterion and predictor variables.

\section{Description of Moderated Regression Analysis}

Sharma et al. (1981) suggest that the Chow test can be used to detect differences across groups in the vector of coefficients of the predictor variables. Importantly, they note that, additionally, a distinction should be made among pure moderators and quasi-moderators, and homologizers, based on the direct and/or moderating effect of the moderator on the predictor and criterion variables. The moderated regression analysis (MRA) procedure suggested by them and summarized in Table F1 can be applied to make this assessment.

Based on the MRA guidelines, we can conclude that the moderator variable is

- $\quad$ a pure moderator, if there is an interaction effect and no direct effect with criterion or predictor variables

- $\quad$ a quasi-moderator, if there is an interaction effect and a direct relationship with the predictor, the criterion variable, or both

- a homologizer, if there is neither a direct effect nor a moderation effect but the detected interaction derives from unequal measurement errors across subsamples.

\section{Application of MRA Procedure and Findings}

Each block in our model contains a criterion variable, a set of predictors, and SES as the moderator. Accordingly, for each of the four blocks, we estimated the three MRA equations and applied the Chow test (Chow 1960) to examine for differences across groups in the vector of coefficients of the predictor variables.

\section{Type of SES Moderation in TPB BLOCK (Block 1)}

Behavioral intention (BI) is the criterion variable; attitude (ATT), subjective norm (SN), perceived behavioral control (PBC), personal network exposure (PNE), and the control variable, Internet PC ownership (IPC), are the five predictors. Based on the MRA procedure, we find

- For direct effects of the predictors on the criterion (BI), all of them, with the exception of SN, are significant.

- $\quad$ For direct effects of the moderator (SES) on the criterion (BI), a significant relationship is not detected.

- For the interaction effects of SES and the predictors, the Chow test indicates that the vector of coefficients for ATT, SN, PBC, PNE, and IPC are different across SES groups.

The above results suggest pure moderation of the relationship between the predictors and the criterion variable in this block.

\section{Type of SES Moderation in ATTITUDE BLOCK (Block 2)}

Attitude (ATT) is the criterion variable; utilitarian outcomes (UO) and hedonic outcomes (HO) are the predictors. Based on the MRA procedure, we find

- $\quad$ For direct effects of the predictors on the criterion (ATT), both UO and HO are significant.

- $\quad$ For direct effects of the moderator (SES) on the criterion (ATT), a significant relationship is not detected.

- $\quad$ For the interaction effects of SES and the predictors, the Chow test indicates that the vector of coefficients for UO and HO are different across SES.

The results suggest pure moderation of the relationship between the predictors and the criterion variable in this block. 


\section{Table F1. Moderated Regression Analysis to Determine the Type of Moderation}

\begin{tabular}{|c|c|c|}
\hline Type of Effect & Equations & Decision Rules \\
\hline Direct Effect of Predictor & $Y=a+b 1 \cdot X$ & \multirow{3}{*}{$\begin{array}{l}\text { - } \mathrm{Z} \text { is not a moderator if } \mathrm{b} 3=0 \text { and } \mathrm{b} 2 \neq 0 \text {. (i.e., } \\
\mathrm{Eq} 2 \text { and } \mathrm{Eq} 3 \text { are not different.) } \\
\mathrm{Z} \text { is a pure moderator, if } \mathrm{b} 2=0 \text { but } \mathrm{b} 3 \neq 0 \text {. (i.e. } \\
\mathrm{Eq1} \text { and } \mathrm{Eq} 2 \text { are not different from each other } \\
\text { but are different from } \mathrm{Eq} 3 \text { ). } \\
\text { - } \mathrm{Z} \text { is a quasi-moderator, if } \mathrm{b} 2 \neq \mathrm{b} 3 \neq 0 \text {. (i.e., All } \\
\text { three equations are different from each other.) }\end{array}$} \\
\hline $\begin{array}{l}\text { Direct Effect of Predictor } \\
\& \text { Moderator }\end{array}$ & $Y=a+b 1 \cdot X+b 2 \cdot Z$ & \\
\hline Interaction & $Y=a+b 1 \cdot X+b 2 \cdot Z+b 3 \cdot X \cdot Z$ & \\
\hline
\end{tabular}

\section{Type of SES Moderation in SUBJECTIVE NORM BLOCK}

SN is the criterion variable; FRPF and governmental influence (GovInf) are the predictors. Based on the MRA procedure, we find

- $\quad$ For direct effects of the predictors on the criterion (SN), FRPF has a significant effect while GovInf does not.

- For direct effects of the moderator (SES) on the criterion (SN), a significant relationship is not detected.

- $\quad$ For the interaction effects of SES and the predictors, the Chow test does not detect significance.

The above results suggest no moderation of the relationship between the predictors and the criterion variable in this block.

\section{Type of SES Moderation in PERCEIVED BEHAVIORAL CONTROL BLOCK}

PBC is the criterion variable; self-efficacy (SE), perceived ease of use (PEOU), and availability are the predictors. Based on the MRA procedure, we find

- $\quad$ For direct effects of the predictors on the criterion (PBC), SE and PEOU have a significant relationship while availability does not.

- $\quad$ For direct effects of the moderator (SES) on the criterion (PBC), a weak significant relationship is detected.

- For the interaction effects of SES and the predictors, the Chow est indicates that the vector of coefficients for SE, PEOU, and availability are different across SES.

The results suggest quasi-moderation of the relationship between the predictors and the criterion variable in this block.

For quasi-moderation, the interaction effect is ambiguous and can be interpreted as (1) SES moderates the relationship between a predictor and PBC, or (2) the predictor moderates the relationship between SES and PBC. To deal with such situations, Sharma et al. (1981) suggest that the interpretation should be "guided by theory rather than empiricism." Given the established body of literature that has theorized and found evidence of the direct effect of internal control and external control on PBC and our own theoretical reasoning for SES to moderate these relationships, we conclude that SES is the moderator.

\section{Evaluation of Moderation Confounds from Multicollinearity and Nonlinear Effects}

High multicollinearity between the moderator and predictor can induce nonlinear effects that confound interaction (Carte and Russell 2003; Cortina 1993). While the correlations between SES and the predictors are low, we did evaluate for the stability of the above moderation results in the presence of nonlinear effects of the predictors. When the squared effect of the predictors is controlled for, the moderation effect remains significant. 